\title{
Controle por antecedentes em produção agregada
}

Adriana de Souza Miranda

Brasília, dezembro de 2016. 


\section{Controle por antecedentes em produção agregada}

Adriana de Souza Miranda

Dissertação de mestrado apresentada ao Programa de Pós-Graduação em Ciências do Comportamento, do Departamento de Processos Psicológicos Básicos, Instituto de Psicologia, Universidade de Brasília, orientado pelo Prof. Dr. João Claudio Todorov e coorientada pela prof. Dra. Láercia Abreu Vasconcelos.

Brasília, novembro de 2016. 
Este trabalho foi desenvolvido no Instituto de Psicologia da Universidade de Brasília com apoio da CAPES.

\section{Comissão Examinadora}

Prof. Dr. João Claudio Todorov (Presidente)

Universidade de Brasília

Raquel Maria de Melo (Membro Efetivo)

Universidade de Brasília

Luciana Patrícia Verneque Formiga (Membro Efetivo) Instituto Brasiliense de Análise do Comportamento (IBAC)

Eileen Pfeiffer Flores (Membro Suplente)

Universidade de Brasília 


\section{Índice}

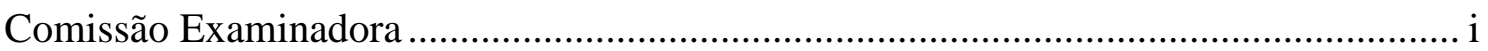

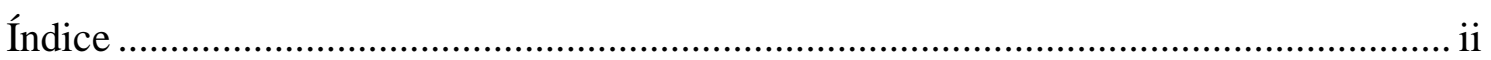

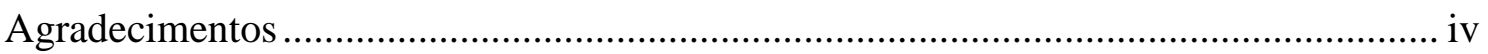

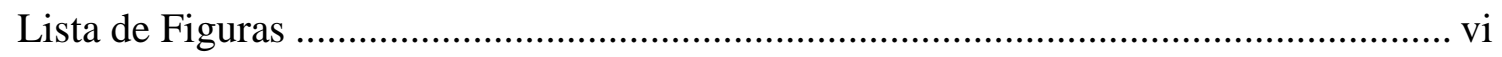

Lista de Tabelas ............................................................................................................. vii

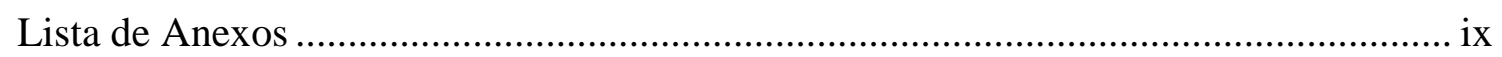

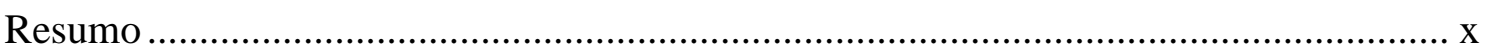

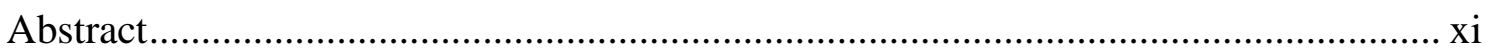

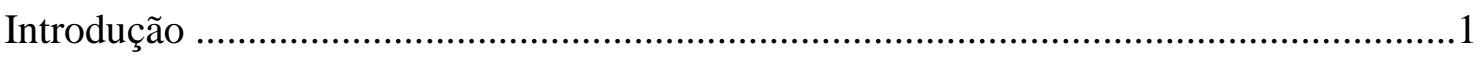

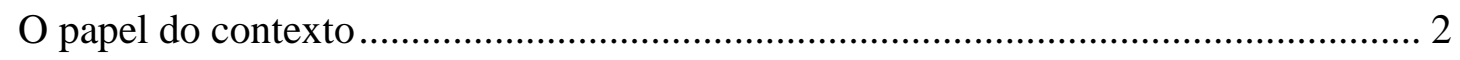

Uma unidade de análise para o terceiro nível de seleção: A Metacontingência............ 6

Controle por antecedentes em práticas culturais .................................................... 11

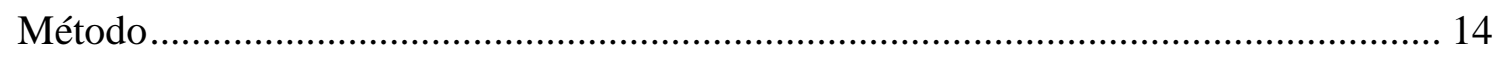

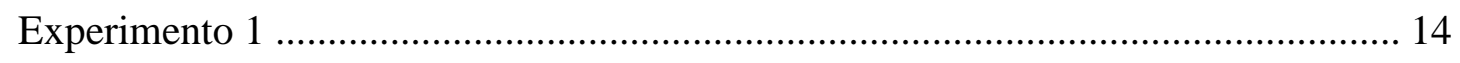

Materiais e instrumentos de pesquisa ....................................................... 15

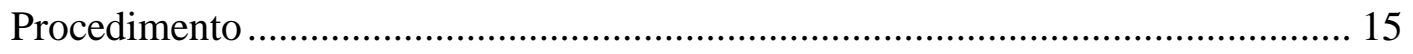

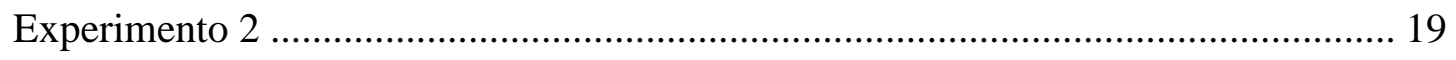

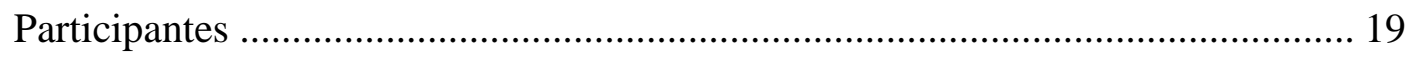

Materiais e instrumentos de pesquisa ............................................................. 19

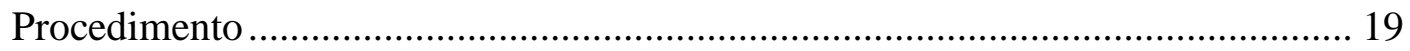


Resultados

Experimento 1

Experimento 2:

Discussão

Anexo - TCLE 50 


\section{Agradecimentos}

Gostaria de agradecer a todos que direta ou indiretamente me auxiliaram nessa jornada.

Agradeço aos meus pais, Helena e Javan, não só pelos anos de educação que permitiram que eu chegasse até aqui, mas por tudo em nossa história que contribuiu com quem eu sou hoje. Meu amor por vocês é eterno e vocês sempre serão meus exemplos.

Aos meus familiares e especialmente à minha avó Neusa, que sempre me incentivou a trilhar meu próprio caminho, a ser uma pessoa independente, correr atrás das oportunidades e que muito me ensinou sobre a vida.

Ao Álvaro, por todo o companheirismo, toda a amizade, todo o apoio: você fez muita diferença neste processo e serei eternamente grata por tudo isso. Obrigada por sempre me mostrar a beleza da ciência de uma forma tão singela.

Agradeço ao professor João Cláudio por me acolher como sua aluna e me orientar ao longo desses anos. Sei da honra que foi trabalhar contigo e sei da sorte de ter um orientador que de fato pude contar.

Agradeço à professora Laércia por aceitar me coorientar. Agradeço gentilmente ao João Vianney, por viabilizar e tornar possível esta pesquisa. Obrigada pela paciência, pelas inúmeras alterações e por todo o suporte.

À Rafaela, por todo apoio que me deu durante a pós e durante minha pesquisa.

Às professoras integrantes da banca, profissionais pelas quais tenho profunda admiração por seus trabalhos de pesquisa "dentro e fora de sala de aula". Gostaria de agradecer mais uma vez pela participação e pelas colaborações em meu trabalho.

Aos amigos que a pós-graduação me presenteou: muito obrigada por tudo! Não cabe aqui o quanto sou agradecida por ter conhecido vocês. Um agradecimento especial 
vai para as meninas do meu coração: Marina, Olívia, Lara, Izabel e Karen. Obrigada pela chance que vocês deram para esta brasiliense.

Aos amigos dos quais a pós-graduação "me afastou": obrigada pela imensa compreensão e carinho durante esse tempo. Obrigada por permanecerem juntos comigo, por lidarem com todos os contratempos desta pós-graduanda da melhor forma possível!

À Morgana, à Nay, e ao Bruno e ao Marco: Vocês são a família que eu pude escolher! Obrigada por sempre acreditarem em mim, mesmo quando eu mesma não conseguia.

À Diana, Bárbara e Clarissa: Obrigada por todo companheirismo durante essa jornada.

Às inestimáveis Carol, Isabela, MaJú e Ludmila: obrigada por estarem ao meu lado durante mais esta conquista profissional. Fomos para caminhos diferentes e com vocês eu aprendi a dialogar, acolher e dividir.

À CAPES, pelo apoio financeiro.

A todos, muito obrigada. 


\section{Lista de Figuras}

Figura 1: Exemplificação da Contingência Tríplice.

Figura 2: Exemplo de Metacontingência. Traduzido e adaptado de Glenn et. al. (2016) 9

Figura 3: Tabuleiros na condição $S^{\mathrm{D}}$ (à esquerda) e $S^{\Delta}$ (à direita)................................ 17

Figura 4: Controle por antecedentes em produção agregada....................................... 18

Figura 5: Taxa de produto agregado por minuto, em cada tentativa ao longo das fases de linha de base (LB), treino discriminativo (TD) e teste discriminativo (TST) no Experimento 1.

Figura 6: Número de movimentos por tentativa em cada condição, ao longo das fases de linha de base (LB), treino discriminativo (TD) e teste discriminativo (TST) no Experimento 1. Atentar para a escalas diferentes no eixo Y. 23

Figura 7: Índices de dispersão de células e de PAs por duplas na condição $S^{\mathrm{D}}$. 25

Figura 8: Taxas de produto agregado por minuto ao longo da apresentação de cada estímulo na fase de Teste de Generalização do Experimento 1. A linha vertical tracejada sinaliza a posição do $S^{\mathrm{D}}$ no gráfico. 28

Figura 9: Taxa de produto agregado por minuto, em tentativa em cada tentativa ao longo das fases de linha de base (LB), treino discriminativo (TD) e teste discriminativo (TST) no Experimento 2.

Figura 10: Número de movimentos para a produção de PA realizados por tentativa em cada condição ao longo das fases de linha de base, treino discriminativo e teste discriminativo no Experimento 2. Atentar para escalas diferentes no eixo Y 34

Figura 11: Índices de dispersão de células e de PAs por duplas no Experimento 2 durante a linha de base, teste discriminativo e teste discriminativo. 35 
Figura 12: Taxas de produto agregado por minuto ao longo da apresentação de cada estímulo na fase de Teste de Generalização do Experimento 2. A linha vertical tracejada sinaliza a posição do $\mathrm{S}^{\mathrm{D}}$ no gráfico. Atentar para escalas diferentes no eixo Y 36 


\section{Lista de Tabelas}

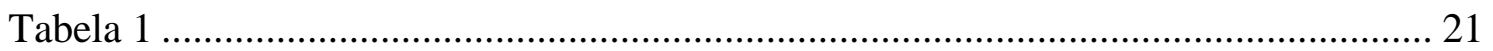


Lista de Anexos

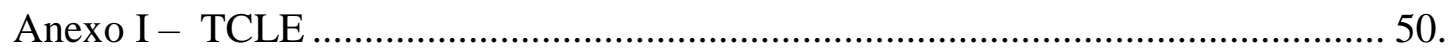




\section{Resumo}

Metacontingências descrevem relações entre contingências comportamentais entrelaçadas, um produto agregado e suas consequências culturais. Esta pesquisa foi uma replicação sistemática de um experimento simplificado sobre metacontingência com objetivo de observar seu controle por antecedentes. Um software simulou um tabuleiro semelhante ao do jogo xadrez e foram manipuladas as consequências para os encontros das peças, de acordo com a cor do fundo da tela do tabuleiro. Foram realizados dois experimentos, com a participação de cinco duplas no Experimento 1, e nove duplas no Experimento 2. Os experimentos eram compostos por quatro fases: de linha de base, treino discriminativo, teste discriminativo e teste de generalização, e diferiram em relação à ordem da apresentação dos estímulos treinados na fase de teste discriminativo (alternada ou aleatória). Foram analisados: Taxa de Produto Agregado (PA), quantidade de movimentos, índice de dispersão das células e da localização dos PAs. Nos dois experimentos foi observada discriminação entre os estímulos, mas não foi observada generalização. $\mathrm{O}$ efeito de contraste comportamental foi observado para a maioria das duplas dos experimentos e o efeito de deslocamento de pico em algumas duplas do Experimento 2. A pesquisa mostra que os estímulos antecedentes também controlam interações sociais, sendo importante para compreensão destes fenômenos.

Palavras-chave: metacontingência, produto agregado, controle de estímulos, controle discriminativo, contraste comportamental 


\begin{abstract}
Metacontingency describe the relation between interlocked behavioral contingencies, their aggregate product and their cultural consequences. A simplified experiment was replicated in order to observe the control by antecedents stimuli in a social interaction set. It was utilized a software to simulate a virtual chessboard. The meeting of the game pieces, considered as the aggregate product, presented different consequences to the participants, depending on the color of the background of the chessboard. The procedure consisted of four phases: baseline, discriminative training, discriminative test and generalization test. Fourteen pairs of undergraduate students participated in this research and were distributed in one of two experiments, which diverged only at the order of the presentation of the stimuli in discriminative test phase (alternately or randomly). Were analyzed: PA rate, number of movements and the dispersion index. The results stated that was a discrimination between the two stimuli, but it wasn't observed generalization rates. The effect of behavioral contrast was observed in most of the pairs in both experiments and the peak shift effect only at some pairs in Experiment 2. This research shows that the antecedents stimuli also control social interactions and that they are important to the comprehension of these phenomena.
\end{abstract}

Key words: Metacontingency, aggregate product, stimuli control, discriminative control, behavioral contrast. 
Para Skinner, o comportamento humano é função de três níveis de seleção por consequências: o filogenético, responsável pela evolução da espécie; o cultural, que seleciona regras para a regulação da vida em sociedade; e o ontogenético, que modela, expande e mantém o comportamento de cada membro da espécie (Skinner, 1981). A ciência do comportamento proposta por Skinner (1938) tem como principal modelo causal a seleção por consequências e propõe-se a investigar os processos básicos do comportamento e identificar os aspectos dos quais o comportamento é função. A partir desta ótica, a Análise Experimental do Comportamento pretende oferecer ferramentas para compreender os determinantes do comportamento, descrever variáveis e relações condicionais, a fim de prevê-los e controlá-los (Skinner, 1953/2000).

Desde o início das pesquisas na Análise Experimental do Comportamento, observa-se que o principal foco tem sido o nível de seleção ontogenético (Todorov, 2008; 2016), tendo como ênfase o comportamento operante - tipo de comportamento que opera sobre o ambiente, modificando-o, e é sensível às suas próprias consequências (Skinner, 1953/2000).

$\mathrm{O}$ conceito de contingência apresenta-se como um instrumento conceitual e permite uma análise básica do comportamento operante. É utilizado para descrever relações do tipo "se...então" (Todorov, 1991; 2012c). Contingências enunciam relações condicionais de dependência entre eventos. No comportamento operante, descrevem a situação em que o comportamento ocorre e relacionam antecedentes e suas consequências ambientais (ver Figura 1) (Skinner, 1938; 1974/1995; Todorov, 2012c). 


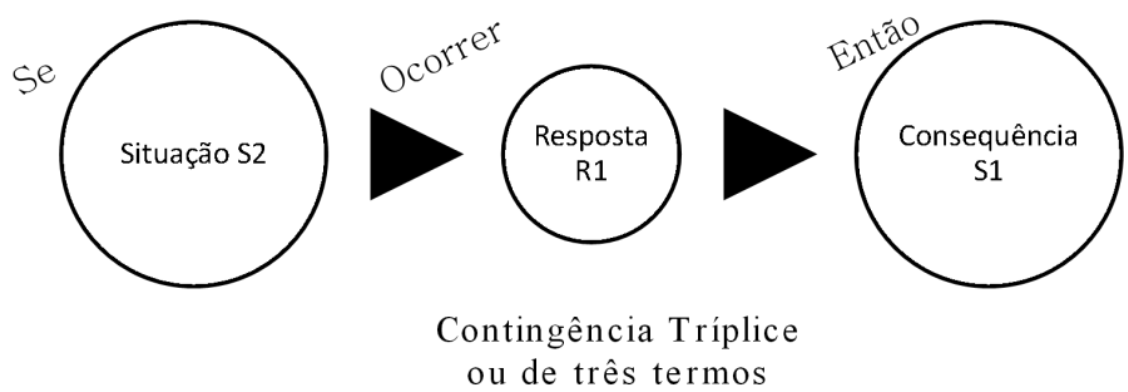

Figura 1: Exemplificação da Contingência Tríplice.

\section{O papel do contexto}

Já é sabido que o contexto também exerce controle sobre a emissão de respostas no comportamento operante (Catania, 1999; Dinsmoor, 1995; Herrnstein, 1961; Moreira \& Medeiros, 2007; Sério, Andery, Gioia, \& Micheletto, 2010; Sidman, 2008; Skinner, 1953/2000). A tríplice contingência, principal ferramenta conceitual de análise neste nível de seleção do comportamento, explicita o papel do contexto na seleção e manutenção do comportamento operante. Só faz sentido pensar, sob a ótica analítico-comportamental, em respostas que são selecionadas em determinadas circunstâncias, uma vez que nenhuma resposta será reforçada toda vez que for emitida (Skinner, 1953/2000). Dá-se o nome de Controle de Estímulos a esta influência exercida pelo contexto na ocorrência dos comportamentos (Catania, 1999; Moreira \& Medeiros, 2007).

Os estudos sobre controle de estímulos e sobre o papel do contexto se desenvolveram principalmente a partir da década de 1950 e 1960 (e.g., Dinsmoor, 1995; Guttman \& Kalish, 1956; Terrace, 1963), em que as pesquisas começaram a investigar não só a relação entre resposta e seus consequentes, mas também a relação entre as respostas e seus antecedentes (Dinsmoor, 1995). A inclusão do ambiente como elemento fundamental na unidade de análise do comportamento estimulou e ampliou pesquisas em áreas como a da psicofísica, psicofarmacologia, neurociências e cognição (Sidman, 
2008). Entretanto, ainda se observa que as investigações acerca do binômio respostaconsequência são mais frequentes (Dinsmoor, 1995; Sidman, 2008).

Fala-se em discriminação quando o controle de estímulos é estabelecido para uma resposta específica (Sério et. al., 2010). Para que esse processo ocorra é necessário que o organismo tenha contato com, ao menos, uma classe de respostas e dois conjuntos de estímulos (Sério et al., p. 13): estímulos que assumem a função de $\mathrm{S}^{\mathrm{D}}$ e estímulos que assumem a função de $S^{\Delta}$. Diz-se que a discriminação foi bem-sucedida quando o organismo passa a responder diferencialmente a estes dois estímulos.

Estímulos discriminativos $\left(\mathrm{S}^{\mathrm{D}} \mathrm{S}\right)$ são eventos ambientais cuja apresentação precede a resposta, sinaliza a probabilidade de reforço para esta mesma resposta e, portanto, também exercem controle sobre sua emissão (Catania, 1999; Moreira \& Medeiros, 2007; Sério et. al., 2010). Os estímulos que estiveram presentes quando uma resposta foi emitida e reforçada sinalizam quando esta mesma classe de respostas terá probabilidade de ser reforçada novamente. Denominam-se de $S^{D_{S}}\left(\right.$ ou $\left.S^{+}\right)$os estímulos correlacionados ao reforço.

Os estímulos Delta $\left(S^{\Delta}, S\right.$ - ou ainda $\left.S^{0}\right)$ são aqueles eventos que, para uma classe de respostas, sinalizam (e estão correlacionados à) ausência do reforço. Sua presença, após o estabelecimento da discriminação, indica que uma resposta tem poucas chances de ser seguida de reforço.

Um procedimento comumente utilizado para obter discriminação entre estímulos - isto é, responder diferencialmente - chama-se de treino discriminativo (Moreira, Todorov \& Nalini, 2006).Um treino de discriminação simples pode ocorrer nos seguintes arranjos: apresentação do reforço em um componente e a não-apresentação de reforço (extinção) em outro componente, a apresentação do reforço em um componente e apresentação de um estímulo correlacionado à estimulação aversiva (punição); ou ainda 
a apresentação de dois esquemas cujas densidades das distribuições de reforços são diferentes.

Em uma discriminação simples, em que há o mínimo de elementos necessários para estabelecer um responder discriminado para uma classe de respostas, os estímulos $S^{\mathrm{D}}$ e $\mathrm{S}^{\Delta}$ podem ser apresentados sucessivamente ou simultaneamente (Sério el. al., 2010). O processo de discriminação sucessiva ocorre quando os estímulos $S^{D}$ e $S^{\Delta}$ são apresentados um após o outro durante um período (isto é, não ficam em vigor ao mesmo tempo) e resultam em um responder discriminado. Já o processo de discriminação simultânea produz um responder discriminado após apresentar $\mathrm{S}^{\mathrm{D}}$ e $\mathrm{S}^{\Delta}$ apresentados ao mesmo tempo por um período.

Quando dois estímulos são apresentados e correlacionados com esquemas de reforçamento diferentes, considerando a mesma classe de respostas, observa-se que geralmente há mudança nas taxas respostas diante desses dois estímulos. A resposta do indivíduo é suscetível a variações na taxa de reforço e qualquer alteração desta resulta em alterações nas taxas de respostas. Chama-se de interação uma mudança na taxa de resposta durante a apresentação de um estímulo em função de mudanças no esquema de reforçamento relacionada a outro estímulo (Catania, 1999). Esta interação pode ser denominada de contraste comportamental quando a taxa de resposta em um componente (E.g., $S^{D}$ ) se altera e varia em direção oposta à taxa de reposta gerada no outro componente (e.g., $\left.S^{\Delta}\right)$. (Reynolds, 1961).

Comparações entre taxas de respostas (respostas emitidas por minuto) e índice de discriminação (taxa de cada um dos estímulos dividida pela soma das taxas dos dois estímulos) podem trazer informações sobre o controle exercido por estímulos. Para observar o controle de estímulos e seus efeitos é comum realizar alguma verificação logo após o treino, uma vez que os sujeitos podem estar sob controle de outros aspectos, tais 
como dimensões dos estímulos apresentados (por exemplo, cor ou forma dos estímulos) ou sob controle da maneira que foram apresentados (como o posicionamento ou ordem de apresentação dos estímulos). Algumas opções para testar o controle de estímulos sobre as respostas derivam de alterações nos esquemas de reforçamento dos componentes ou, ainda, costuma-se realizar um teste em que o reforço é suspenso para todos os estímulos e novos são adicionados (Catania, 1999).

A generalização é um princípio comportamental que se caracteriza pela dispersão de parte do efeito do reforço para outros estímulos (não treinados). Ou seja, outros estímulos também se tornam efetivos em exercer controle sobre respostas. Esse controle exercido por outros estímulos tem efeito gradativo e depende do grau de similaridade com o estímulo inicial (Keller \& Schoenfeld, 1950).

Um teste de generalização consiste em apresentar $S^{\mathrm{D}}$ (com suspensão do reforço) e $S^{\Delta}$, além de outros estímulos (que são variações das dimensões dos estímulos anteriores) e verificar como as respostas ocorrem ao longo das apresentações (Catania, 1999; Moreira \& Medeiros, 2007). O gradiente de generalização diz respeito à distribuição de respostas durante um teste de generalização e informa o quanto do efeito do reforço se estendeu para os outros estímulos apresentados (Catania, 1999).

Alguns trabalhos (e.g., Guttman \& Kalish, 1956) tiveram como objetivo pesquisar essas relações de controle de estímulos. A maioria dos experimentos que envolveram treinos discriminativos tiveram interesse em observar efeitos da generalização (Azevedo, 2015). Para investigar quais outros estímulos se tornaram efetivos as pesquisas geralmente manipulam durante a fase de teste de generalização dimensões dos estímulos tais como cor, forma, dimensão e brilho (Sério, et. al., 2010). É necessário que o procedimento seja bem planejado para que se saiba qual dimensão do estímulo treinado 
vai exercer controle sobre as respostas e como o efeito do reforço será distribuído aos outros estímulos (Catania, 1999; Moreira, Todorov, \& Nalini, 2006).

Assim, pelo controle que os estímulos antecedentes exercem, as pesquisas sobre controle de estímulos são de fundamental importância para maior compreensão sobre o comportamento. Diz-se que os estímulos antecedentes à resposta estabelecem a ocasião para que ela ocorra (Catania, 1999), uma vez que eles sinalizam quais respostas tem a maior probabilidade de ocorrência em um determinado contexto.

\section{Uma unidade de análise para o terceiro nível de seleção: A Metacontingência.}

Contingências são enunciados do tipo “se...então...” que descrevem relações entre eventos e são muito utilizadas na Análise do Comportamento (Todorov J. , 1991; 2012a). Elas são utilizadas tanto para o estudo do comportamento respondente (explicitando a relação entre eventos ambientais ou entre eventos ambientais e o comportamento), quanto para o estudo do comportamento operante (explicitando a relação entre contexto, respostas e suas consequências) (Todorov, 2012a).

Também é possível observar relações condicionais (isto é, contingências comportamentais) no comportamento de pessoas em grupo. Comportamentos que envolvem mais de uma pessoa podem ser compreendidos como fenômenos sociais e também fazem parte do escopo da ciência do comportamento proposta por Skinner (Sampaio \& Andery, 2010).

Três eventos podem ser caracterizados de acordo com a Análise do Comportamento como fenômenos sociais (Sampaio \& Andery, 2010): o comportamento social, a produção agregada; e a prática cultural. O comportamento social é um comportamento operante caracterizado por contingências tríplices cujas consequências são mediadas pelo comportamento operante de outro indivíduo (Skinner, 1953/2000). O produto agregado (PA) é o resultado gerado (Produto Agregado), o efeito produzido no 
ambiente por esses comportamentos. A prática cultural, por sua vez, é tida como a classe de respostas aprendidas - isto é, conjunto de comportamentos similares aprendidos propagada por vários e sucessivos indivíduos: são comportamentos que, ao se substituir um indivíduo por outro, tem alta probabilidade de ser produzir o PA, em variáveis durações de tempo, sejam anos, meses, dias (Todorov, 2013). Práticas culturais podem ser compreendidas como contingências socialmente determinadas, que prevalecem em uma sociedade, um grupo ou uma organização (Todorov, 2012b, p. 97).

Um texto publicado por Sigrid Glenn em 1986 marca o início dos estudos em nível cultural, a fim de compreender e investigar tais fenômenos sociais dentro da Análise do Comportamento. Esta publicação é significativa, pois propõe à comunidade científica uma nova unidade de análise para explicar contingências sociais: a metacontingência.

O conceito de metacontingência trata de um tipo de contingência que se aplica ao comportamento de grupo (Todorov, 2012a) - apesar de não descrever todos os tipos de relações funcionais que caracterizam os fenômenos sociais. Ela especifica que tipo de consequências determinado produto agregado (PA) vai ter para pessoas em um grupo (Todorov, 2012a; 2012b; 2013). Este produto agregado deve ser fruto de contingências comportamentais entrelaçadas (CCEs) e é selecionado por um ambiente cultural.

A utilização de metacontingência como uma nova unidade de análise tem permitido a investigação de comportamentos sociais e de grupos, bem como práticas sociais, sem fazer recortes dicotômicos (indivíduo versus sociedade) ou reducionistas. Foram realizados estudos tanto na área aplicada quanto na área experimental. Em todos os estudos apresentados a seguir, foi salientada a importância de se investigar comportamentos e práticas culturais, além de ressaltada suas propriedades complexas, longe de serem esgotadas em análises contingenciais simples (Vasconcelos \& Todorov, 2015). 
Algumas reformulações no conceito de metacontingência foram sugeridas desde o seu primeiro emprego em 1986. Problemas conceituais em relação ao termo foram levantados (Todorov, 2012b; 2013): o termo metacontingência vem sendo utilizado para falar tanto de diferentes processos quanto de procedimentos; fenômenos sociais de longa duração, com ou sem recorrência; estudos de interações em contexto experimental; estudos de contingências presentes em leis, normas e regulamentos estão caracterizados sob o mesmo rótulo (Todorov, 2012b).

Em 2016 foi publicado um artigo (Glenn, et al., 2016) fruto do empenho dos pesquisadores da área para tentar chegar a um consenso quanto às terminologias utilizadas em pesquisas envolvendo fenômenos sociais. Priorizou-se a discussão dos termos: metacontingência, macrocontingência e macro comportamento.

Atualmente, o termo metacontingência foi redefinido como "a relação contingente entre: a) contingências comportamentais (CCEs) recorrentes produzindo um produto agregado e b) eventos ou condições ambientais selecionadoras" (Glenn et. al., 2016). No exemplo da Figura 2, temos a metacontingência envolvida em uma empresa que presta serviços de transporte e entregas de produto: as CCEs são indicadas pelos vários entrelaçamentos necessários para que o PA (encomenda) seja entregue ao consumidor (que corresponderia ao ambiente cultural selecionador). 


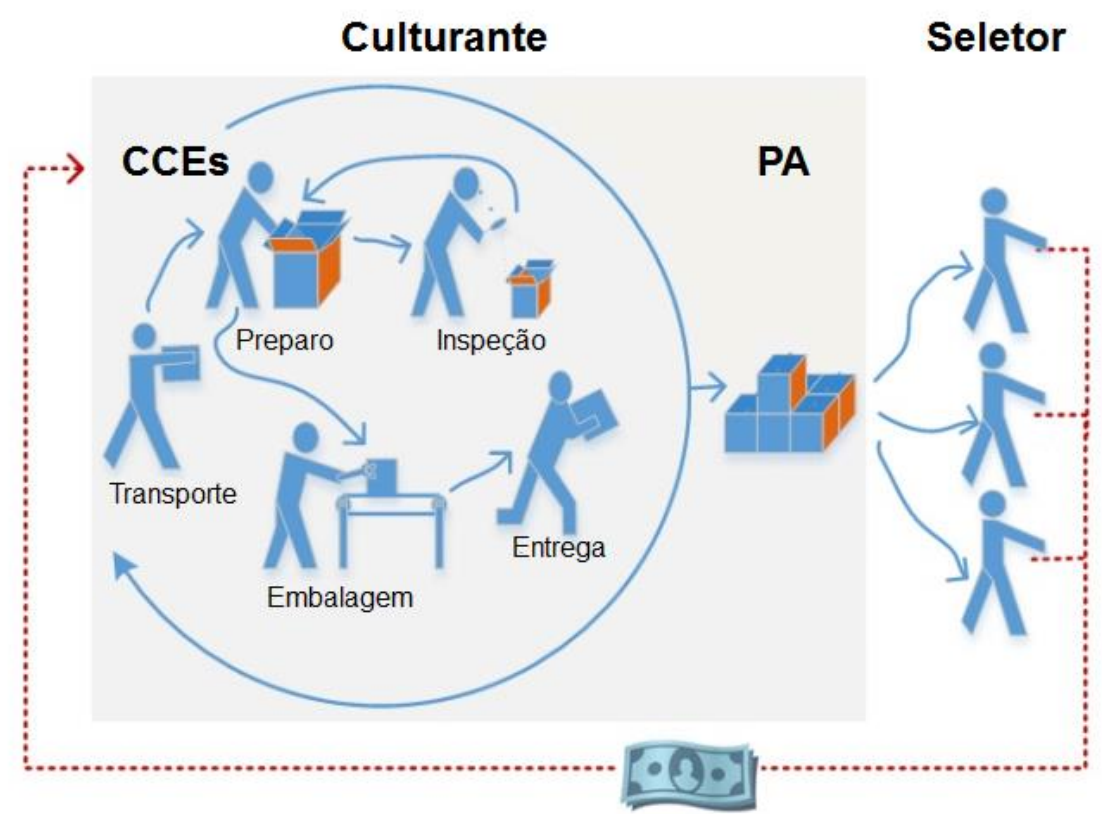

Figura 2: Exemplo de Metacontingência. Traduzido e adaptado de Glenn et. al. (2016)

Apesar da atual publicação (Glenn et al., 2016) ainda envolver discussão de aspectos conceituais para análises de práticas culturais, muitas pesquisas foram realizadas ao longo desses 30 anos com base na proposta inicial do termo "metacontingência". Algumas delas são mencionadas abaixo.

Todorov (1987) utiliza o conceito de metacontingência para analisar a Constituição brasileira de 1988. A Constituição também pode ser considerada como um conjunto de regulações as quais descrevem conjuntos de metacontingências, uma vez que elas descrevem certas contingências comportamentais entrelaçadas, assim como consequências e Produtos Agregados.

Outro estudo aplicado é apresentado por Forero, Garcia, Silva e López-López (2012), ao analisar a lei de "Justiça e Paz" na Colômbia. Esta Lei surgiu em resposta às violações sistemáticas de direitos humanos no país e define consequências, assim como procedimento judicial especial, aos responsáveis por delitos tais como sequestro, homicídio e outros definidos como atrozes. Os autores observaram que algumas contingências estão descritas de forma incompleta e que esta falta de clareza ao descrever 
os elementos pode comprometer a implementação das leis. Além destes, outros trabalhos buscaram identificar metacontingências em textos legais foram realizados (e.g., Carvalho, 2013; Cabral, 2014; Todorov, Moreira, Prudêncio, \& Pereira, 2004).

Trabalhos que envolveram revisões de literatura do uso do termo (metacontingência) e de experimentos realizados também marcam a produção a respeito do estudo de práticas culturais (e.g., Martone \& Todorov, 2007).

A metacontingência tem sido utilizada também como instrumento de análise em contextos experimentais com humanos (Andrade, 2015; Azevedo, 2015; Franceschini, Samelo, Xavier, \& Huzinker, 2012; Oliveira, 2015; Ortu, Becker, Woelz, \& Glenn, 2012; Vasconcelos \& Todorov, 2015; Vichi, Andery, \& Glenn, 2009; Vieira, 2010). São, geralmente, utilizadas situações de jogos em que as regras emitidas funcionariam como o meio cultural selecionador do Produto Agregado e produziriam as consequências e os reforços são arbitrários (Vasconcelos e Todorov, 2015). As contingências comportamentais entrelaçadas (CCEs) têm sido manipuladas e observadas em tarefas de duplas ou grupos (e.g., Franceschini, Samelo, Xavier, \& Huzinker, 2012; Vichi, Andery, \& Glenn, 2009).

Outras tarefas experimentais envolvem o procedimento do dilema do prisioneiro (e.g., Costa D. C., 2009; Sampaio, 2016; Costa, Nogueira, \& Vasconcelos, 2012; Nogueira, 2009; Ortu, Becker, Woelz, \& Glenn, 2012); troca de gerações de participantes (e.g., Pavanelli, Leite, \& Tourinho, 2014; Toledo, et al., 2015; Vichi, 2012); desenvolvimento de softwares e utilização de ambiente virtual (Andrade, 2015; Azevedo, 2015; Oliveira, 2015; Toledo et. al., 2015; Vasconcelos \& Todorov, 2015; Vieira, 2010); controle de estímulos em interações sociais; (e. g., Azevedo, 2015; Leite, 2014; Vieira, 2010); procedimentos simplificados com redução de variáveis, com manipulação apenas 
a consequência cultural e sem troca de gerações (Azevedo, 2015; Andrade, 2015; Oliveira, 2015; Vasconcelos \& Todorov, 2015).

\section{Controle por antecedentes em práticas culturais}

Assim como no estudo do comportamento operante, em que análises iniciais foram realizadas apenas com dois termos (resposta e consequentes), observa-se o mesmo caminho sob a ótica do terceiro nível de seleção dos comportamentos (cultural). A definição apresentada por Gleen et. al. (2016) trata da relação entre o PA e a consequência cultural e não inclui, apesar de não negar, o terceiro termo referente aos antecedentes nesta ferramenta teórico-metodológica.

Considerando o nível de complexidade dos experimentos em metacontingência (manipulações de consequências culturais e individuais; troca de gerações de participantes, entre outros), Azevedo (2015) ressalta a importância da investigação do controle exercido por antecedentes e propõe um experimento simplificado, a fim de observar processos discriminativos em atividades de grupos. A tarefa experimental era uma atividade colaborativa entre dois participantes e o estudo era composto por quatro fases: linha de base, treino de discriminação, teste de discriminação e teste de generalização.

Os participantes eram solicitados a mover duas peças em um tabuleiro virtual Software Xadrez - (Todorov \& Vianney, 2013), de 8x8 células, até que as duas peças se encontrassem. Cada participante movia apenas uma peça e, no início de cada rodada, cada uma delas se encontrava nas extremidades do tabuleiro. Na presença do estímulo discriminativo (cor azul ao fundo do tabuleiro), os encontros eram seguidos de um reforço (mensagem na tela: "Parabéns! O objetivo foi alcançado!"). Na presença da cor amarela no fundo do tabuleiro, os encontros não foram seguidos de reforço: os encontros das peças na presença dessa cor sinalizavam, então, a ausência do reforço, e as peças voltavam 
automaticamente para a posição inicial. Durante a fase da linha de base, todos os encontros foram reforçados, independentemente do local do tabuleiro onde as peças se encontravam e não havia mudança de cor do fundo do jogo (a cor azul permaneceu durante toda esta fase). Na fase de treino discriminativo, apenas quando a cor de fundo azul $\left(S^{d}\right)$ eram seguidos de reforço; os encontros realizados quando a cor de fundo amarela $\left(\mathrm{S}^{\Delta}\right)$ não geravam o Produto Agregado e as peças retornavam à posição inicial. Na fase de teste de discriminação cada cor de fundo do jogo ficou em vigor por 60s, alternadamente, cinco vezes cada. Já no teste de generalização, foram apresentadas sete cores $\left(582 \mathrm{~nm}\left(\mathrm{~S}^{\Delta}\right), 566 \mathrm{~nm}, 533 \mathrm{~nm}, 500 \mathrm{~nm}, 484 \mathrm{~nm}\left(S^{\mathrm{D}}\right), 468 \mathrm{~nm}\right.$ e $\left.451 \mathrm{~nm}.\right)$ e a apresentação da consequência cultural (mensagem de parabéns) foi suspensa.

Os resultados obtidos por Azevedo (2015) indicam que houve um responder diferencial na presença dos dois estímulos manipulados $\left(\mathrm{S}^{\mathrm{D}}\right.$ e $\left.\mathrm{S}^{\Delta}\right)$, colaborando com a ideia de se observar um processo semelhante ao comportamento operante. Foi possível utilizar um procedimento simplificado para observar a produção de um Produto Agregado, sem que manipulassem consequências individuais. Porém, alguns dos dados obtidos na fase de teste de generalização não foram sistemáticos (Azevedo, 2015) e a experimentadora sugere que isto pode ter acontecido devido à mudança nos critérios de encerramento das fases de treino e teste, assim como a possibilidade da fase de treino ter sido curta demais.

O estudo de fenômenos sociais a partir de uma nova unidade de análise permitiu que a Análise do Comportamento contasse com novas ferramentas para o estudo sobre o terceiro nível de seleção do comportamento (cultural). Contudo, muitos dos experimentos realizados utilizam-se da manipulação de consequências individuais ou experimentos muito complexos, cujas manipulações podem atuar como variáveis estranhas. 
Apesar dos estudos apresentados, os estudos ainda estão longe de serem esgotados (Todorov, 2012; 2013). Cada vez mais se torna importante investir na área de investigação de seleção cultural, a fim de poder compreender as contingências atuantes neste nível, além de obter informações sobre os esquemas de reforçamento individuais. O assunto também é relevante para pensar e propor em formas de atuações que visem consequências de longo-prazo que beneficiem o grupo, e não apenas os indivíduos envolvidos na produção do produto agregado. Políticas públicas, por exemplo, ao descreverem quais consequências determinadas ações terão em situações específicas, podem ser entendidas como exemplos de metacontingência e também podem se constituir como objeto de estudo e intervenções à luz da Análise do Comportamento.

O presente estudo pretende contribuir com as pesquisas básicas em metacontingência, facilitando, assim, a compreensão de práticas culturais, a partir de um experimento simplificado.

São objetivos deste trabalho realizar uma replicação sistemática de Azevedo (2015), observar o processo de discriminação de estímulos no terceiro nível de seleção do comportamento e refinar um experimento básico a fim de se obter informações sobre processos em metacontingência. 


\section{Método}

Foi recriado o experimento proposto por Azevedo (2015), a fim de observar a ocorrência de Produto Agregado (encontros de peças do xadrez) em condição de discriminação de estímulos antecedentes. Foram realizados dois experimentos.

A nomeação das duplas de participantes (em D1, D2, e assim por diante) não segue a ordem da coleta e foi designada de modo aleatório, a fim de minimizar qualquer identificação dos voluntários. Nos dois experimentos, todas as duplas passaram pelas seguintes fases: linha de base, treino discriminativo, teste discriminativo e teste de generalização.

\section{Experimento 1}

Participantes

Foram convidados para participar da pesquisa alunos de graduação da Universidade de Brasília, a partir de convites verbais realizados em salas de aula. A escolha dos participantes foi por conveniência, obedecendo aos critérios de: a) ser um estudante da instituição; b) interesse e disponibilidade para a realização da atividade.

Participaram 5 duplas de alunos voluntários, inscritos em alguma disciplina do Instituto de Psicologia. Os participantes tinham idades entre 17 e 26 anos. O projeto relativo a esta pesquisa foi submetido e aprovado em Comitê de Ética em Pesquisa com humanos e todos participantes leram e assinaram o Termo de Consentimento Livre e Esclarecido (Anexo 1). Cada voluntário participou da pesquisa apenas uma vez (em dupla).

Ao final da pesquisa, os participantes receberam um certificado de participação, o qual informava a duração da atividade realizada nesta pesquisa. 
Materiais e instrumentos de pesquisa

Para a coleta dos dados, utilizou-se um notebook Samsung, com as seguintes especificações: processador Intel Core i5, 2.50GHz, 6GB de RAM, com sistema Microsoft Windows 10. O notebook foi equipado com o software "Xadrez" (Todorov \& Vianney, 2013), que simula um tabuleiro virtual de $8 \times 8$ células. Os resultados obtidos foram registrados automaticamente pelo software, sendo eles: o número de movimentos realizados; local de ocorrência de cada encontro; número de tentativas; número de acertos; número de erros; tempo de duração de cada movimento; tempo de apresentação de cada estímulo (cores do fundo do tabuleiro manipuladas) e; tempo decorrido de cada fase. A coleta foi feita no em uma sala do departamento de processos psicológicos básicos da Universidade de Brasília.

Procedimento

Foi solicitado aos voluntários que participassem de um jogo colaborativo. A atividade consistia em movimentar duas peças pelo tabuleiro virtual por meio de cliques nas células em que o participante desejasse posicionar a peça. Foi entregue aos participantes uma ficha, contendo as seguintes instruções:

“Olá! A partir de agora, vocês realizarão uma atividade juntos. Este jogo tem um caráter cooperativo, portanto, vocês estão jogando juntos e não um contra o outro. Cada jogador terá uma "carinha" no tabuleiro e deverá movimentá-la através de clicks no mouse. Para movê-la, basta dar um toque em cima da célula que deverá receber a peça. Cada “carinha” move-se fazendo um ' $L$ ' em qualquer direção. $O$ movimento em ' $L$ ' move a peça por três casas em cada jogada (por exemplo, uma casa para frente e duas para o lado). Uma roda da começa com a peça de cada jogador localizada nos extremos do tabuleiro. O jogador que ficar com a peça do extremo superior esquerdo sempre começa as rodadas. Os jogadores movem suas peças alternadamente. O objetivo do jogo é que 
as peças se encontrem no momento certo. As peças não ocupam a mesma célula e o encontro pode ocorrer em qualquer posição (horizontal vertical ou diagonal). Ao final de cada rodada, caso ela tenha sido bem sucedida, vocês receberão a mensagem: “PARABÉNS! O objetivo foi alcançado!'. Clique na mensagem para começar uma nova rodada.

A duração do jogo dependerá do desempenho de vocês. O programa informará quando o jogo chegar ao fim. Mas, vocês podem encerrar o experimento a qualquer momento, caso desejem.

Alguma dúvida? Em caso de dúvidas, releiam as instruções! Vocês podem consulta-las em qualquer momento durante a atividade. Decidam quem ficará com cada peça do tabuleiro. Cada jogador deve continuar com a mesma peça até o fim do jogo. Quando estiverem prontos, cliquem na tela para começar".

O experimento teve início quando os participantes clicaram, utilizando o mouse, na tela do tabuleiro virtual. Após o primeiro clique na tela, os dados dos movimentos realizados pelas peças virtuais foram registrados instantaneamente no output do software. Cada participante movimentou sua peça clicando com o mouse na célula em que desejava posicioná-la. Eram possíveis movimentos apenas em "L", como o movimento da peça "cavalo" no jogo de Xadrez convencional. O experimento contou com as seguintes fases: linha de base; treino discriminativo; teste discriminativo e teste de generalização.

A cor azul (comprimento de onda da cor: $484 \mathrm{~nm}$ ) foi utilizada como $\mathrm{S}^{\mathrm{D}}$ e a cor amarela como $\mathrm{S}^{\Delta}$ (comprimento de onda: $582 \mathrm{~nm}$ ) (Figura 3). Foi também introduzido um blackout de 100 milissegundos entre as tentativas e um contador de pontos no canto superior direito. 
Condição $S^{D}$

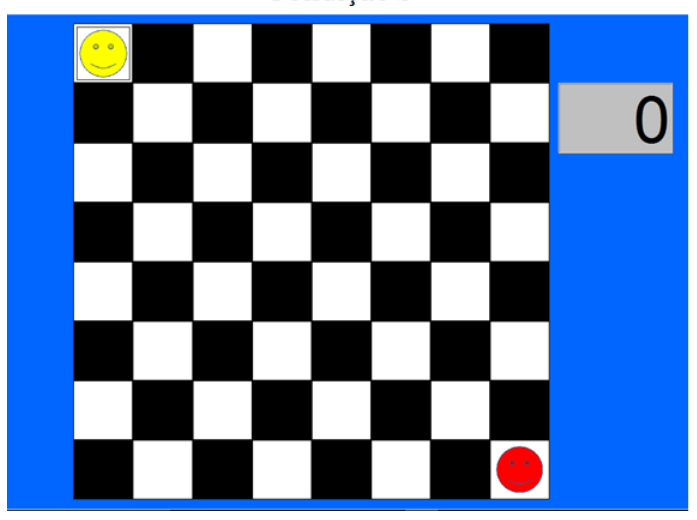

Condição $\mathrm{S}^{\Delta}$

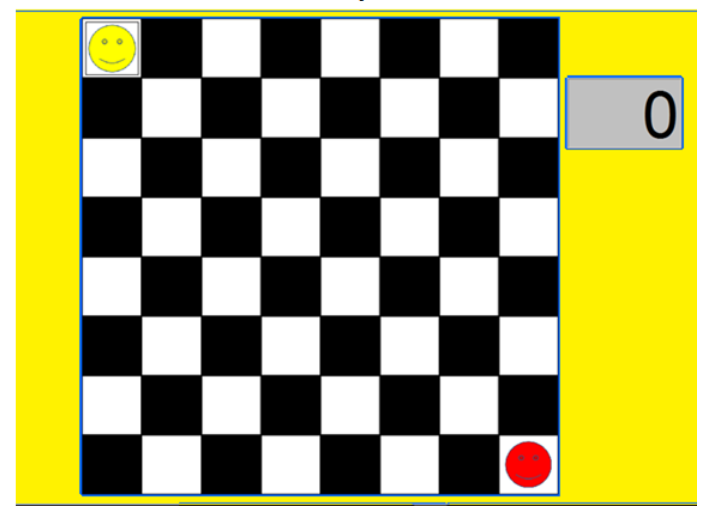

Figura 3: Tabuleiros na condição $S^{\mathrm{D}}$ (à esquerda) e $S^{\Delta}$ (à direita).

Linha de base: Nesta etapa do jogo os participantes receberam a mensagem "Parabéns! O objetivo foi alcançado" toda vez que as peças se encontraram em qualquer local do tabuleiro virtual e era adicionado um ponto ao contador de pontos concomitantemente à apresentação da mensagem. Durante esta etapa, o fundo da tela do jogo permaneceu na condição de $S^{\mathrm{D}}$ (ou seja, com a cor azul). Esta fase terminou quando os participantes realizaram dez encontros das peças (dez produções agregadas).

Treino discriminativo: Nesta fase foi realizado um treino discriminativo com apresentação alternada de $S^{D}$ e $S^{\Delta}$. Encontros das peças na condição de $S^{\Delta}$ não geraram a consequência programada (os participantes não recebem a mensagem na tela) e, caso ocorressem encontros nesta condição, as peças retornariam automaticamente para a posição inicial. Esperou-se que, ao final do treino, os participantes realizassem encontros (produções agregadas) com maior frequência na condição de $\mathrm{S}^{\mathrm{D}}$ (fundo da tela azul) e encontros em menor frequência na condição de $S^{\Delta}$ (fundo da tela amarelo). 

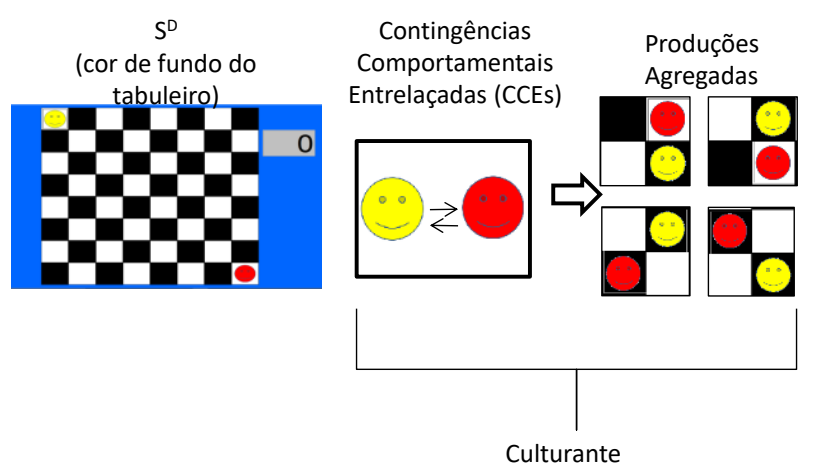

Consequências

Selecionadoras
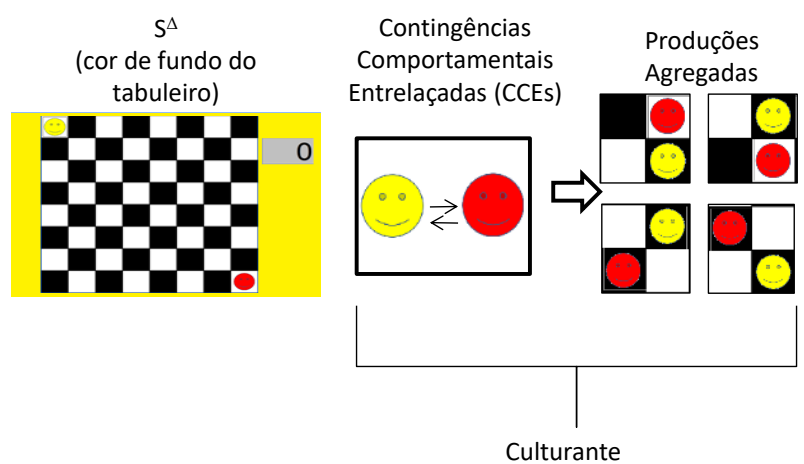

Consequências Selecionadoras (Não são

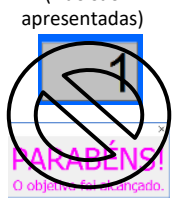

Figura 4: Controle por antecedentes em produção agregada

O treino iniciou com na condição de $S^{\mathrm{D}}$ e, a partir do primeiro encontro, mudou para a condição de $S^{\Delta}$. O critério para encerrar a condição de $S^{\Delta}$ foi permanecer por tempo programado sem realizar o encontro das peças (tempo de inatividade, em relação à ausência de produção do PA) e, cumprido esse critério, o jogo retornou automaticamente para a condição de $S^{\mathrm{D}}$. Inicialmente os participantes deveriam permanecer $3 \mathrm{~s}$ segundos sem a emissão da produção agregada na presença de $S^{\Delta}$. Durante esta fase o tempo de inatividade necessário para mudança de tela progrediu de $3 \mathrm{em} 3$ segundos, até que os participantes ficassem 45 segundos sem produzir encontros (PA) na condição de $\mathrm{S}^{\Delta}$. Após três apresentações seguidas do $S^{\Delta}$ com inatividade de 45 segundos a fase foi encerrada.

Teste discriminativo: Nesta fase foram feitos testes para verificar se os participantes respondiam diferencialmente aos $\mathrm{S}^{\mathrm{D}}$ e $\mathrm{S}^{\Delta}$, conforme o treino discriminativo. Os estímulos foram apresentados alternadamente no Experimento 1 e durante tempos 
iguais de exposição. A fase se encerrou após os participantes cumprirem o critério de tempo de 10 minutos.

Teste de generalização: Nesta fase, foram apresentadas aos participantes deste experimento novas cinco cores de (além do amarelo e azul), as quais se localizam entre os espectros das cores utilizadas nas fases anteriores para sinalizar o $S^{D}$ e o $S^{\Delta}$. Os comprimentos de onda das cores utilizadas nesta fase foram: $582 \mathrm{~nm}\left(\mathrm{~S}^{\Delta}\right), 566 \mathrm{~nm}, 533 \mathrm{~nm}$, 500nm, 484nm $\left(\mathrm{S}^{\mathrm{D}}\right), 468 \mathrm{~nm}$ e $451 \mathrm{~nm}$. Não foi apresentada consequência para encontros (PAs) nesta fase. A fase se encerrou após as apresentações aleatórias de todas as novas cores durante intervalos de 60 s cada e de duas apresentações do $S^{\mathrm{D}}$.

\section{Experimento 2}

Participantes

Participaram do Experimento 2 nove duplas de alunos voluntários. O projeto relativo a esta pesquisa foi submetido e aprovado em Comitê de Ética em Pesquisa com humanos e todos participantes leram e assinaram o Termo de Consentimento Livre e Esclarecido (Anexo 1).

Materiais e instrumentos de pesquisa

Notebook equipado com o software Xadrez (Todorov \& Vianney, 2013) e cartão de instruções.

Procedimento

O procedimento do Experimento 2 diferencia-se do anterior apenas na fase de teste discriminativo: nesta fase, os estímulos foram apresentados de maneira aleatória. 


\section{Resultados}

Os dados analisados nos dois experimentos foram: a taxa de Produto Agregado em cada fase da sessão experimental; números de encontros (PA) e número de movimentos realizados em cada fase (CCEs); número de movimentos realizados em cada tentativa e o índice de dispersão. Deu-se o nome de tentativa (ou rodada) para cada período em que um estímulo foi apresentado. Abaixo estão descritas as medidas:

- Taxa de produção agregada: Números de encontros (PA) por minuto em cada tentativa (Linha de base; Treino discriminativo, teste discriminativo e teste de generalização).

- Número de encontros em cada condição: números de PA em cada condição (condição de $S^{\mathrm{D}}$ e de $\mathrm{S}^{\Delta}$ ).

- Número de movimentos realizados em cada rodada (ou tentativa): Número de movimentos realizados até a produção agregada

- Índice de dispersões: dispersão no uso das células durante os encontros e a dispersão na localização dos PAs na condição de $\mathrm{S}^{\mathrm{D}}$.

Foram feitas comparações intraduplas e entre duplas, a fim de se observar os efeitos de cada manipulação (apresentação do $S^{\mathrm{D}}$ e $S^{\Delta}$ ) em cada fase e as tendências gerais de cada uma das fases.

O tempo médio das sessões nos dois experimentos foi de 55'57', (tempo mínimo:39'49',; tempo máximo: 83'21' '). O tempo médio das duplas em cada fase foi de: 4’32', (tempo mínimo: 2’26’'; tempo máximo: 07’37’'), na linha de base; 27’00’' (mínimo: 12'51'’; máximo: 77’26’) no treino discriminativo. As fases de teste discriminativo e teste de generalização tiveram tempo fixo de 10 e 14 minutos, respectivamente. A Tabela 1 apresenta a distribuição do tempo nas duas primeiras fases e o tempo total da atividade realizada por cada dupla. 
Tabela 1

Duração da linha de base, treino discriminativo e duração total da atividade por dupla

\begin{tabular}{|c|c|c|c|}
\hline \multicolumn{4}{|c|}{$\begin{array}{l}\text { Duração da linha de Base, Treino Discriminativo e duração tota } \\
\text { da atividade por dupla }\end{array}$} \\
\hline & $\begin{array}{l}\text { Linha de } \\
\text { Base }\end{array}$ & Treino Discriminativo & Total \\
\hline D1 & $05: 11$ & $01: 17: 26$ & $1: 52: 37$ \\
\hline D2 & 05:39 & $17: 12$ & $0: 46: 51$ \\
\hline D3 & $05: 11$ & 20:09 & $0: 49: 20$ \\
\hline D4 & 04:26 & 13:30 & $0: 41: 56$ \\
\hline D5 & $06: 56$ & $16: 59$ & $0: 47: 56$ \\
\hline D6 & $02: 47$ & $25: 12$ & $0: 51: 59$ \\
\hline D7 & $02: 26$ & $16: 54$ & $0: 43: 20$ \\
\hline D8 & $02: 58$ & $12: 51$ & $0: 39: 49$ \\
\hline D9 & 03:30 & $24: 23$ & $0: 51: 54$ \\
\hline D10 & $06: 58$ & $28: 58$ & $0: 59: 56$ \\
\hline D11 & 02:49 & $56: 30$ & $1: 23: 21$ \\
\hline D12 & 07:37 & $18: 50$ & $0: 50: 28$ \\
\hline D13 & 04:12 & 18:09 & $0: 46: 21$ \\
\hline D14 & $02: 43$ & $30: 51$ & $0: 57: 34$ \\
\hline Total & $1: 03: 23$ & $6: 17: 54$ & 13:03:22 \\
\hline Média & 04:32 & 00:27:00 & 00:55:57 \\
\hline
\end{tabular}

Seguem abaixo os resultados encontrados durante a etapa de coleta desta pesquisa em cada um dos experimentos.

\section{Experimento 1}

O tempo médio das sessões deste experimento foi de 47’12'” (tempo mínimo: 41'56'; tempo máximo: 50’28'’). O tempo médio das duplas em cada fase foi de: 5'40' (tempo mínimo: 3'30’'; tempo máximo: 07’37’) na linha de base; 17’31'" (mínimo: 12'51'"; máximo: 20'09') no treino discriminativo. As fases de teste discriminativo e teste de generalização tiveram tempo fixo de 10 e 14 minutos, respectivamente.

A Figura 5 mostra taxa de produção agregada durante as fases de linha de base, treino e teste discriminativo neste experimento ao longo das tentativas. As linhas contínuas representam as taxas de PA na presença de $\mathrm{S}^{\mathrm{D}}$ e as linhas tracejadas representam as taxas de PA em $\mathrm{S}^{\Delta}$. 


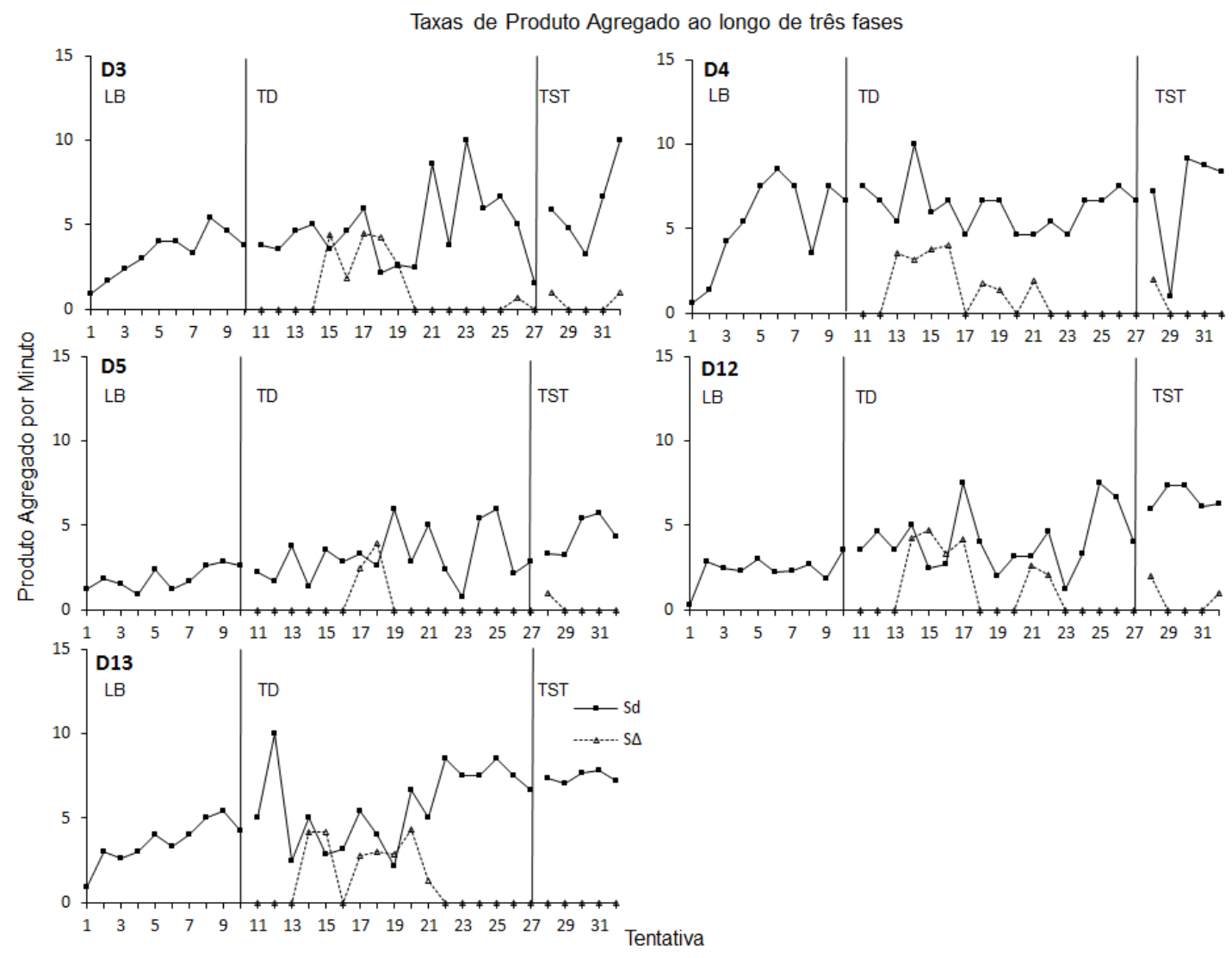

Figura 5: Taxa de produto agregado por minuto, em cada tentativa ao longo das fases de linha de base (LB), treino discriminativo (TD) e teste discriminativo (TST) no Experimento 1.

Todas as duplas apresentaram baixa oscilação da taxa de PA ao longo da linha de base e aumentaram sistematicamente desde o início da fase. As duplas D3, D12 e D13 apresentaram o aumento visível da taxa de PA desde a segunda tentativa. Observa-se que D5 e D13 tiveram o maior valor da taxa de PA na $9^{\mathrm{a}}$ tentativa, e D12 na $10^{\mathrm{a}}$. Todas as duplas atingiram o critério de 10 encontros para a mudança de fase.

Além das taxas de produto agregado por minuto, foram medidas as quantidades de movimentos realizados pelas duplas em cada tentativa (Figura 6). Durante a linha de base, observa-se na Figura 6 que a maioria das duplas termina a fase emitindo menos movimentações que no começo da fase. Todas as duplas emitiram, em média, cinco movimentações por tentativa. 
Movimentos pelo tabuleiro ao longo de três fases
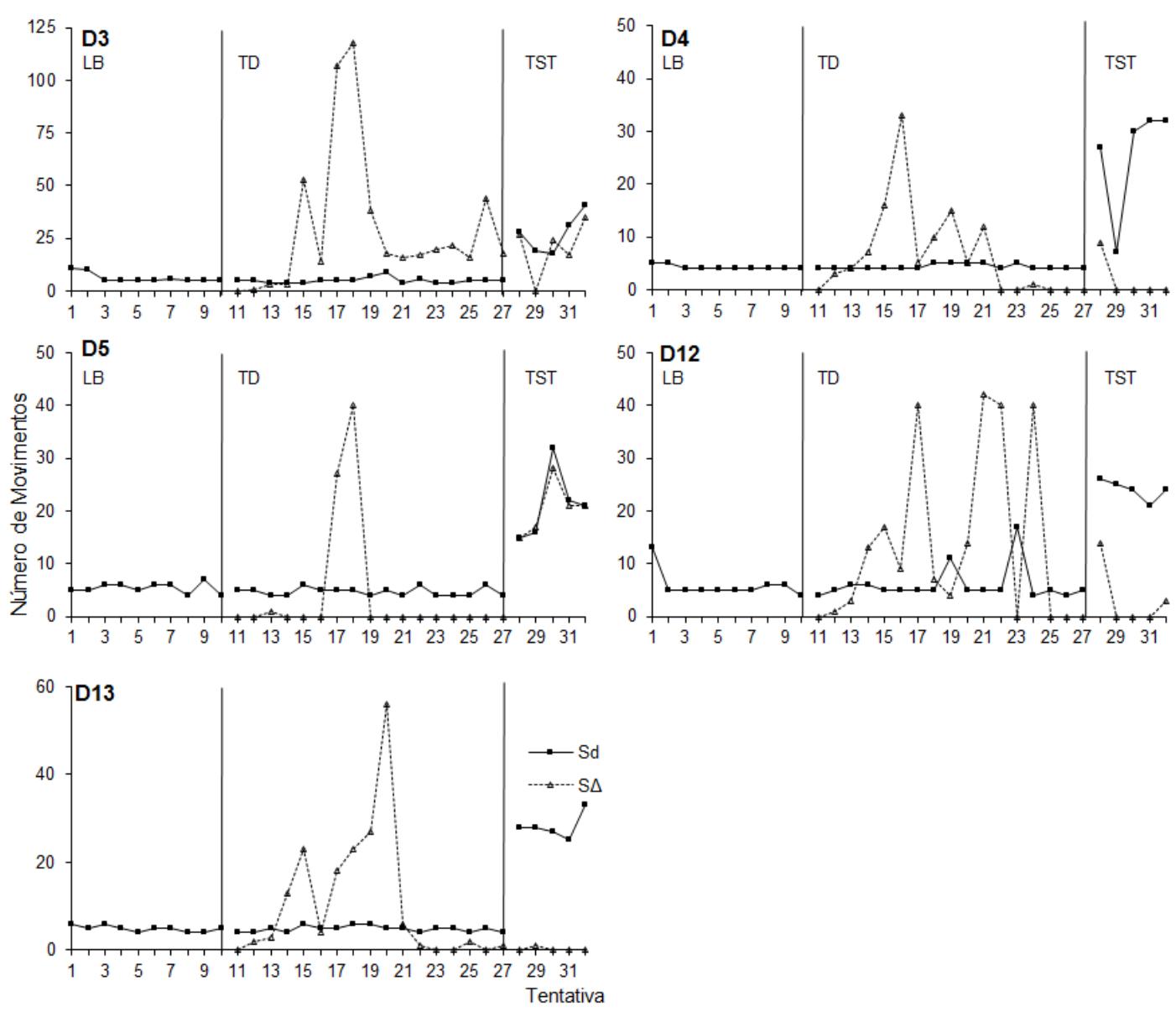

Figura 6: Número de movimentos por tentativa em cada condição, ao longo das fases de linha de base (LB), treino discriminativo (TD) e teste discriminativo (TST) no Experimento 1. Atentar para a escalas diferentes no eixo Y.

Em relação às movimentações das peças pelo tabuleiro ao longo das fases (Figura 6), observa-se as duplas apresentaram pouca variação de movimentações entre as tentativas na linha de base, sendo a quantidade de movimentações mantidas sem grandes variações a partir da terceira tentativa para a maioria das duplas.

O Índice de dispersão das células (Figura 7) foi calculado a partir da divisão entre o número das células diferentes usadas nos encontros pelo total de células possíveis daquela fase (número de células diferentes/total possível de células da fase). O número total de células possíveis foi diferente para cada dupla, uma vez que ele depende da quantidade de PAs que foram produzidos em cada fase e em cada apresentação dos 
estímulos. Observa-se na linha de base que a dupla D4 foi a dupla que obteve o menor índice de dispersão das células, ou seja, foi a dupla que realizou menos variações nas células utilizadas durante os encontros.

O índice de dispersão dos PAs (Figura 7) foi calculado a partir da relação entre a quantidade de PAs realizados em locais diferentes pelo número total de locais onde os PAs ocorreram nas apresentações de cada estímulo durante a linha de base, treino e teste discriminativo. Assim como o índice de dispersão das células, a dupla D4 também foi a que apresentou a menor variação no local do tabuleiro em que realizou os encontros.

No treino discriminativo (Figura 5), as duplas D4 e D13 tiveram as taxas de PA durante a apresentação do $S^{\mathrm{D}}$ mais altas deste experimento e D3 e D13 foram as que apresentaram maior variação da taxa de PA na presença de $S^{\mathrm{D}}$. As duplas D3, D12 e D13 voltam a aumentar suas taxas de PA próximos à $20^{\mathrm{a}}$ tentativa, enquanto D4 e D5 apresentaram menores variações da taxa ao longo da fase. As duplas que apresentaram maior taxa de PA em $\mathrm{S}^{\Delta}$ foram as duplas D12 e D13 e a dupla que apresentou menor taxa de PA e a menor variação em $\mathrm{S}^{\Delta}$ ao longo da fase foi a dupla D5.

Com a apresentação de $S^{\Delta}$ na fase de treino discriminativo (Figura 5), pode-se observar que há um aumento inicial na taxa de $\mathrm{PA}$ em $\mathrm{S}^{\Delta}$ aproximadamente entre a $13^{\mathrm{a}}$ e a $20^{\mathrm{a}}$ para todas as duplas e que este aumento na taxa de $\mathrm{PA}$ em $\mathrm{S}^{\Delta}$ é acompanhado por decréscimos na taxa de PA em $\mathrm{S}^{\mathrm{D}}$. Por volta da $20^{\mathrm{a}}$ tentativa a taxa de $\mathrm{PA}$ em $\mathrm{S}^{\Delta}$ cai consideravelmente e permanece igual ou a próxima a zero até o final da fase. A fase de treino discriminativo se encerra com a queda das taxas de PA em $\mathrm{S}^{\Delta}$, contrastando com os as taxas de PA no $\mathrm{S}^{\mathrm{D}}$. Todas as duplas atingiram o critério de estabilidade da fase - três tentativas consecutivas de $45^{\prime}$ ' sem produção agregada no $\mathrm{S}^{\Delta}$. D3 foi a única dupla que apresentou taxa de $\mathrm{PA}$ em $\mathrm{S}^{\Delta}$ maior que 0 , na tentativa de $\mathrm{n}^{\circ} 26$ (taxa de 0,69 ). 
Dispersão de Células

Dispersão de PAs
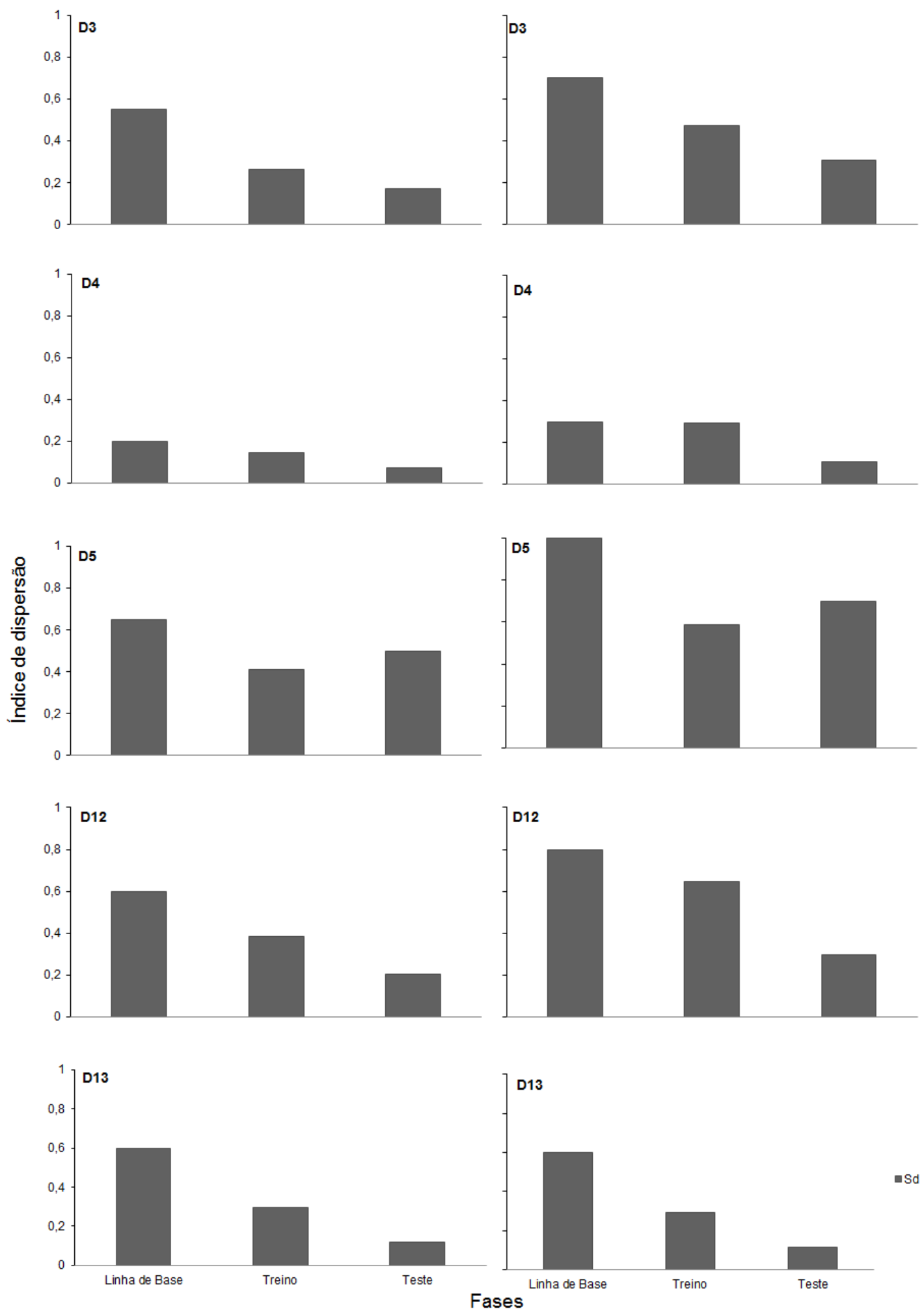

Figura 7: Índices de dispersão de células e de PAs por duplas na condição $S^{\mathrm{D}}$. 
O efeito de contraste comportamental foi observado ao final do treino discriminativo para 4 de 5 duplas (D3, D5, D12 e D13): houve aumento na taxa de PA em $S^{D}$ em função da introdução de outro esquema de reforçamento (correlacionado ao $\mathrm{S}^{\Delta}$ ) e as taxas de PA nessas duplas durante apresentação de $\mathrm{S}^{\mathrm{D}}$ variaram em sentido oposto as taxas produzidas durante a apresentação de $S^{\Delta}$.

No treino discriminativo (Figura 6) as cinco duplas mantiveram a mesma média da linha de base para a quantidade de movimentos em $S^{\mathrm{D}}$ durante toda a fase, com exceção de D12, que em duas tentativas $\left(19^{\mathrm{a}}\right.$ e $\left.23^{\mathrm{a}}\right)$ apresentou aumento relativo às movimentações passadas. Todas as duplas terminam a fase mantendo a mesma média de movimentos na presença de $S^{\mathrm{D}}$ que apresentaram durante a fase de treino discriminativo e linha de base.

Embora não se observe grandes oscilações na quantidade de movimentos realizados no treino discriminativo enquanto o $S^{D}$ era apresentado, durante a apresentação do $S^{\Delta}$ observa-se alto índice de movimentações com a introdução do $S^{\Delta}$ principalmente a partir da terceira apresentação de $S^{\Delta}$. Esta alta movimentação cai para próximo de zero nas seis últimas tentativas da fase para D4, D5,e D13.

As altas taxas de PA e de movimentação em $\mathrm{S}^{\Delta}$ no meio do treino (a partir da $13^{\mathrm{a}}$ tentativa), assim como os índices de dispersão observados na Figura 7, indicam que as duplas ficaram realizando encontros, variando suas localizações e o posicionamento das peças. Essas taxas em $\mathrm{S}^{\Delta}$ diminuem após algumas tentativas enquanto durante a apresentação de $\mathrm{S}^{\mathrm{D}}$ as taxas de $\mathrm{PA}$ aumentam e permanecem maiores (quando comparadas com $\mathrm{S}^{\Delta}{ }_{-}$. A quantidade de movimentos e as células utilizadas nos encontros também se mantêm as mesmas (apesar de alguma variabilidade na localização dos PAs). Esses dados indicam a discriminação por parte dos participantes em relação às cores de fundo do tabuleiro. 
As taxas de produção agregada do teste discriminativo em $\mathrm{S}^{\mathrm{D}}$ foram maiores que as taxas de produção agregada em $\mathrm{S}^{\Delta}$. As duplas que apresentaram maiores taxas de PA na presença de $S^{\mathrm{D}}$ foram D13 e D12. Em D3 e D4, as duplas com maior variação na taxa de PA, respectivamente na $30^{\mathrm{a}}$ e $29^{\mathrm{a}}$ tentativas, observa-se uma queda na taxa de $\mathrm{S}^{\mathrm{D}}$ seguido de novo aumento.

Para todas as duplas durante o teste discriminativo observa-se um aumento significativo no número de movimentos realizados na presença de $\mathrm{S}^{\mathrm{D}}$, quando comparada às fases anteriores na presença de $\mathrm{S}^{\mathrm{D}}$. Para D4, D12 e D13 a quantidade de movimentos realizados na presença de $S^{\mathrm{D}}$ é visivelmente maior que a quantidade de movimentos realizados na presença de $\mathrm{S}^{\Delta}$. Para D3 e D5 os números de movimentos realizados tanto em $S^{D}$ quanto em $S^{\Delta}$ são próximos. Nestas duas últimas duplas, observa-se maiores oscilações no movimento das peças na presença de $\mathrm{S}^{\mathrm{D}} \mathrm{S}^{\Delta}$ ao longo das tentativas.

Os resultados obtidos no teste de generalização são apresentados na Figura 8, mostrando as taxas de PAs por minuto na apresentação em cada estímulo. Nesta fase, além de $S^{\mathrm{D}}$ e $\mathrm{S}^{\Delta}$, foram introduzidos outros cinco estímulos, todos com a suspensão do reforço para os encontros. Todos os estímulos foram apresentados às duplas de forma aleatória. Apesar das duplas D4 e D12 apresentarem maiores taxas de PA quando expostas ao $\mathrm{S}^{\mathrm{D}}$, os dados encontrados do teste de generalização foram assistemáticos uma vez que a produção de PA variou ao longo das apresentações dos estímulos.

Nesta fase, nota-se que D4 foi a única dupla que apresentou taxas de PAs mais altas à medida que se afastava de $\mathrm{S}^{\Delta}$, sendo suas duas taxas maiores observadas exatamente nos espectros mais distantes de $S^{\Delta}$. A taxa mais alta da fase foi obtida por D3, no estímulo antecedente (500nm) ao espectro de $S^{\mathrm{D}}(484 \mathrm{~nm})$. A dupla D12 apresentou a taxa de PA maior em $S^{\mathrm{D}}$ e a menor taxa de PA em $S^{\Delta}$, contudo, entre $S^{\Delta}$ e $S^{\mathrm{D}}$ observa- 
se um aumento nas taxas (espectros de $655 \mathrm{~nm}$ e $53 \mathrm{~nm}$ ) seguido de decréscimo logo antes do $S^{\mathrm{D}}(\mathrm{em} 500 \mathrm{~nm})$.

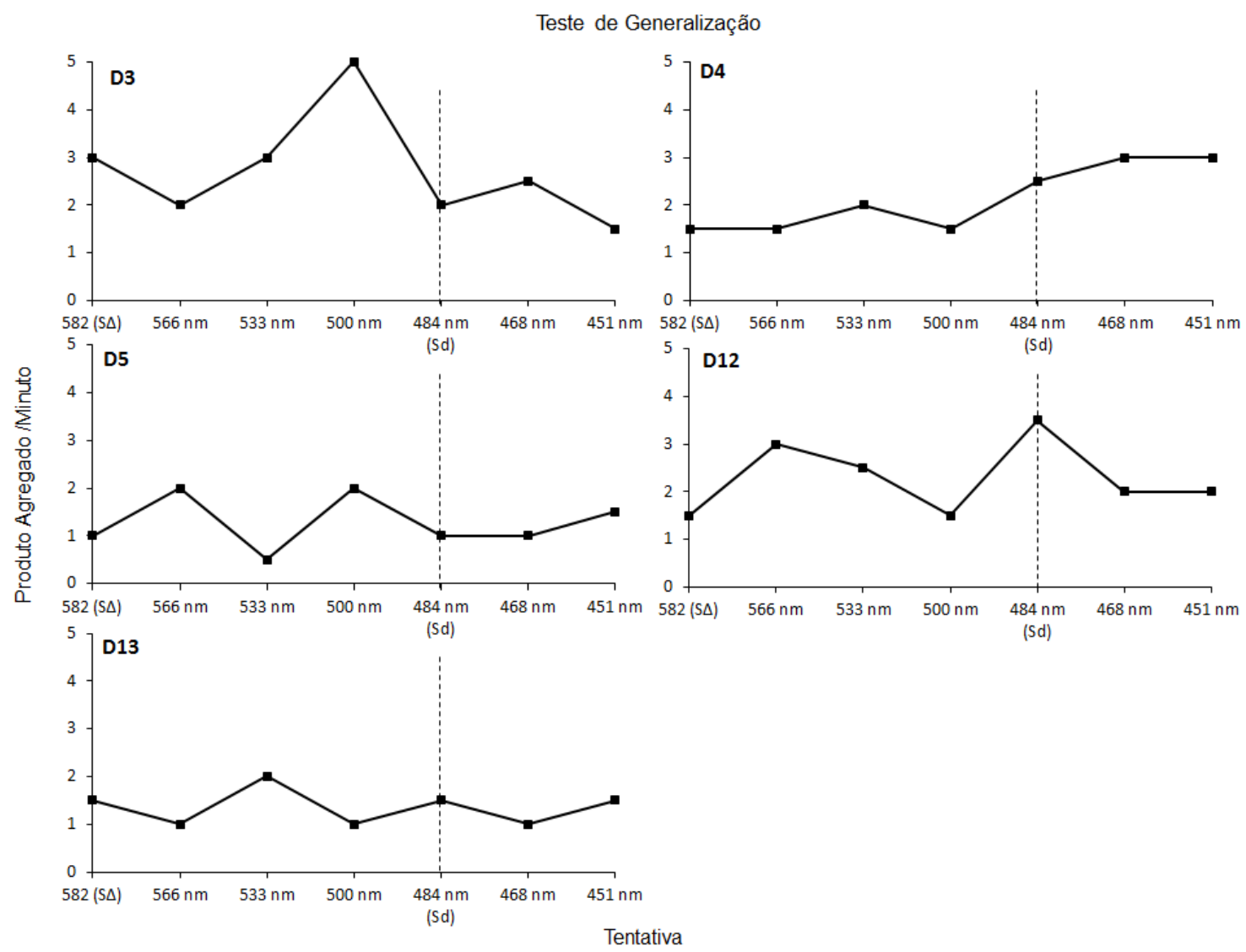

Figura 8: Taxas de produto agregado por minuto ao longo da apresentação de cada estímulo na fase de Teste de Generalização do Experimento 1. A linha vertical tracejada sinaliza a posição do $S^{\mathrm{D}}$ no gráfico.

A dupla que apresentou a menor taxa de PA em $\mathrm{S}^{\Delta}$ foi a dupla D5 (1 encontro/minuto), e a que apresentou maior taxa de PA em $S^{\Delta}$ foi a dupla D3 (3 encontros/minuto). D12 apresentou a maior taxa de PA em $\mathrm{S}^{\mathrm{D}}$ e D5 apresentou a menor taxa de PA em $\mathrm{S}^{\mathrm{D}}$. Duas duplas (D3 e D13) apresentaram taxas de PA maiores em $\mathrm{S}^{\Delta}$ que em SD; Duas duplas (D4 e D12) as taxas de PA foram maiores em $\mathrm{S}^{\mathrm{D}}$ que em $\mathrm{S}^{\Delta}$ e uma dupla (D5) apresentou taxas de PA iguais em $S^{\mathrm{D}}$ e $\mathrm{S}^{\Delta}$.

\section{Experimento 2:}


As duplas que participaram do Experimento 2 (D1, D2, D6, D7, D8, D9, D10, D11 e D14) passaram por apresentação aleatória dos estímulos $S^{\mathrm{D}}$ e $\mathrm{S}^{\Delta}$ durante a fase de teste discriminativo. Este teste de discriminação teve duração total de 10 minutos e foi adotado o critério de apresentação aleatória dos estímulos; Para atingir este critério de aleatoriedade, nem sempre o programa apresentou os estímulos igualdade em número de exposição: Ou seja, houve duplas em que um estímulo $\left(S^{D}\right.$ ou $\left.S^{\Delta}\right)$ foi apresentado mais que o outro (D2, D6, D8 D10 e D11 - com mais exposições ao $\mathrm{S}^{\Delta}$; D7 e D14 com mais exposições ao $S^{\mathrm{D}}$ ).

O tempo médio das sessões deste experimento foi de 60’00'’(tempo mínimo: 39'49'; tempo máximo: 112'37'). O tempo médio das duplas em cada fase foi de: 3'53'(tempo mínimo: 02’26'; tempo máximo: 06'58''), na linha de base; 32'15' (mínimo: 12’51'; máximo: 77’26’') no treino discriminativo. As fases de teste discriminativo e teste de generalização tiveram tempo fixo de 10 e 14 minutos, respectivamente (exceto pela dupla D1, que passou por 20 minutos na fase de teste de generalização devido a um erro do programa ao finalizar a atividade).

A Figura 9 apresenta as taxas de PA para $S^{D}$ e $S^{\Delta}$ ao longo das fases de linha de base, treino discriminativo e teste discriminativo. A linha contínua representa as taxas de $\mathrm{PA}$ em $\mathrm{S}^{\mathrm{D}}$ e a tracejada as taxas de PA em $\mathrm{S}^{\Delta}$.

As duplas que apresentaram maiores taxas médias de PA (Figura 9) na linha de base foram D7 e D8 e as duplas com menores taxas médias nesta fase foram D11 e D10.

A única dupla na qual se observa uma queda na taxa de PA durante a linha de base é a dupla D11. Observa-se um aumento da taxa ao longo da fase em D1, D2, D6, D7. As duplas que apresentaram as maiores taxas de PA na linha de base foram D7 e D8 e as duplas que apresentaram as taxas mais baixas de PA foram D11 e D10. As duplas que 
apresentaram menores variações nas taxas de PA ao longo da fase foram D14, D11 D10. Todas as duplas atingiram o critério de 10 tentativas para mudança de fase.

A Figura 10 apresenta o número de movimentações realizadas pelas duplas ao longo das tentativas, nas fases de linha de base, treino discriminativo e teste discriminativo. Todas as duplas, durante a linha de base, mantiveram aproximadamente as mesmas quantidades de movimentos, com poucas variações. D8 e D10 são as duplas que terminam a fase com um ligeiro aumento em relação ao início da fase.

A Figura 11 apresenta os índices de dispersão das células e de localização dos PAs ao longo das fases de linha de base, treino discriminativo e teste discriminativo para $\mathrm{S}^{\mathrm{D}}$. Em linhas gerais, as duplas apresentaram pouca variação na utilização de células e nas posições dos encontros. Ou seja, as duplas optaram por repetir as células e os locais em que realizaram os encontros.

Na fase de treino discriminativo, as duplas com maiores taxas média de produção agregada em $\mathrm{S}^{\mathrm{D}}$ foram D7 e D11 e as duplas com menores taxas médias de PA na presença do $\mathrm{S}^{\mathrm{D}}$ foram D10 e D1.

Durante a apresentação do $\mathrm{S}^{\Delta}$, as duplas que apresentaram as maiores taxas médias no treino discriminativo foram D11 e D7 e no teste discriminativo foram D6, D14. Já as menores taxas no treino discriminativo foram obtidas por D2 e D8 e no teste discriminativo foram D1 e D7 .

A taxa de $\mathrm{PA}$ em $\mathrm{S}^{\Delta}$ (figura 9) para todas as duplas apresenta aumento próximo à $13^{\text {a }}$ tentativa, se mantém alta durante em tentativas seguintes, mas termina a fase com queda, próximo a zero. As duplas que apresentaram as maiores taxas foram D11, D7 e D1; enquanto D8, D2 e D14 apresentaram as menores. Observa-se em D7, D8 picos na taxa de PA em $\mathrm{S}^{\Delta}$, em grande oposição à taxa de $\mathrm{S}^{\mathrm{D}}$ nas tentativas correspondentes. 
Foram as duplas que mais variaram a taxa de PA nesta condição, enquanto foram as duplas que menos variaram.

Observa-se o efeito de contraste comportamental em relação ao componente fixo $\left(S^{D}\right)$ ao final do treino discriminativo para 5 de 9 duplas ( D2, D6, D7, D9 e D11): ao final do treino, as taxas de $\mathrm{PA}$ em $\mathrm{S}^{\mathrm{D}}$ foram maiores que durante a linha de base e variaram em direção oposta às taxas de PA em $\mathrm{S}^{\Delta}$.

$\mathrm{Na}$ fase de teste discriminativo cada um dos estímulos $\left(\mathrm{S}^{\mathrm{D}}\right.$ e $\left.\mathrm{S}^{\Delta:}\right)$ ficou em vigor por 60 segundos. Para D1 e D9, os estímulos foram apresentados em equivalência de tempo; D2, D6, D8, D10, D11 tiveram com mais exposições ao $\mathrm{S}^{\Delta}$; e D7 e D14 com mais exposições ao $\mathrm{S}^{\mathrm{D}}$.

Para duas duplas em que foram expostas mais vezes ao $S^{\mathrm{D}}$, a taxa de PA em $\mathrm{S}^{\mathrm{D}}$ foi mais alta que em $\mathrm{S}^{\Delta}$. D14 e D9, D10 e D11 apresentaram taxas de PA maiores no teste que no treino discriminativo. Apenas em D2 e D14 observa-se uma aproximação no início do teste discriminativo entre taxas de $S^{D}$ e $S^{\Delta}$ e nenhuma dupla apresentou taxa de PA em $\mathrm{S}^{\Delta}$ maior que a taxa de $\mathrm{S}^{\mathrm{D}}$.

As duplas que apresentaram, durante o teste discriminativo, as maiores taxas de PA em $\mathrm{S}^{\mathrm{D}}$ foram as duplas D11, D6 e D9. Já as duplas com menores taxas de PA em $\mathrm{S}^{\mathrm{D}}$ foram as duplas D1, D7 e D10. As duplas com maiores taxas de PA na presença de $\mathrm{S}^{\Delta}$ foram D6,D14 e D11, e as duplas com as menores taxas de PA na presença de $\mathrm{S}^{\Delta}$ foram D1, D8 e D7. 


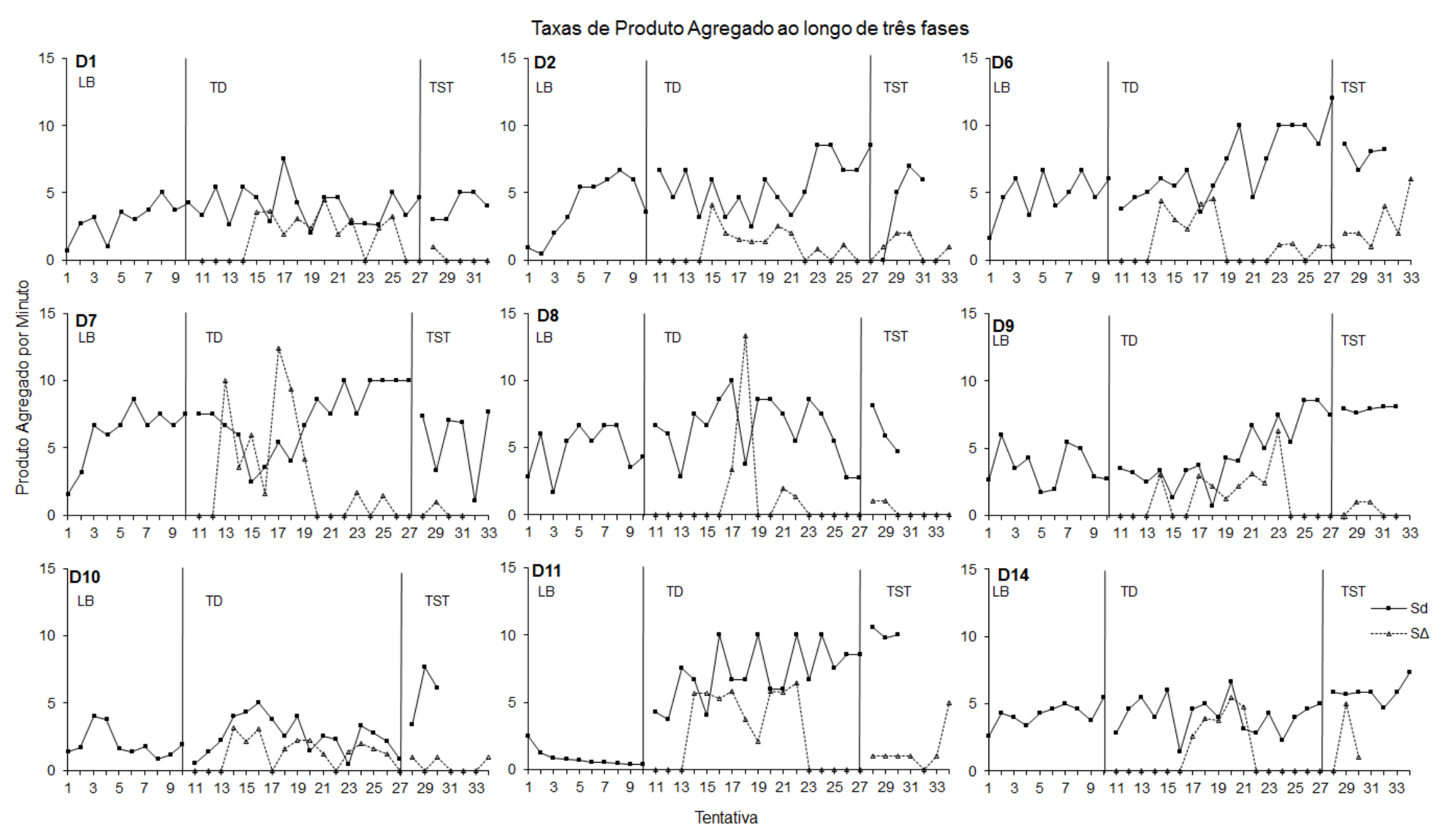

Figura 9: Taxa de produto agregado por minuto, em tentativa em cada tentativa ao longo das fases de linha de base (LB), treino discriminativo (TD) e teste discriminativo (TST) no Experimento 2. 
Durante o teste discriminativo (Figura 10) todas as duplas aumentaram a média de movimentos realizados na presença de $\mathrm{S}^{\mathrm{D}}$, quando comparada com as fases anteriores. A dupla D14 realizou mais movimentos na presença de $S^{\Delta}$ que na presença de $S^{D}$ e o contrário pode ser observado nas duplas D1, D2, D8, D9, D10, D11. D6 apresenta um aumento constante na quantidade de movimentos tanto para $S^{D}$ quanto para $S^{\Delta}$

As taxas de PA também foram calculadas para o teste de generalização (Figura 9). Foram apresentados os mesmos cinco estímulos apresentados durante o Experimento 1 nesta fase, além de $S^{\mathrm{D}}(582 \mathrm{~nm})$ e $S^{\Delta}(484 \mathrm{~nm})$. A fase de teste de generalização teve duração de 14 minutos, exceto para D1, que durou 20 minutos e contou com duas exposições a mais para os estímulos $484 \mathrm{~nm}\left(\mathrm{~S}^{\mathrm{d}}\right), 468 \mathrm{~nm}$ e $451 \mathrm{~nm}$ devido à falha do programa.

Quanto às taxas de PA em $\mathrm{S}^{\mathrm{D}}$, D9 foi a dupla que apresentou a maior taxa, enquanto D1 foi a que apresentou a menor. Já em relação às taxas de PA em $\mathrm{S}^{\Delta}$, a dupla com maior taxa foi D2 e a com menor foi D9.

D2 e D11 apresentaram as maiores taxas na presença do estímulo mais afastado (451 nm) de $\mathrm{S}^{\Delta}$, contudo as taxas de PA em $\mathrm{S}^{\mathrm{D}}$ também foram as menores das duplas. Para D6, D7, D9, D10 e D14 as taxas de PA em $\mathrm{S}^{\mathrm{D}}$ foram maiores que as taxas de PA durante a apresentação de $S^{\Delta}$. Para D2, e D11, as taxas de PA em $S^{\Delta}$ foram maiores que em $S^{\mathrm{D}}$. A dupla D8 não apresentou variação na taxa de PA durante a apresentação de todos os estímulos, mantendo taxa de PA constante durante toda a fase. No geral, observase que não houve generalização do efeito do reforço para os estímulos próximos ao $S^{\mathrm{D}}$ na maioria das duplas. 

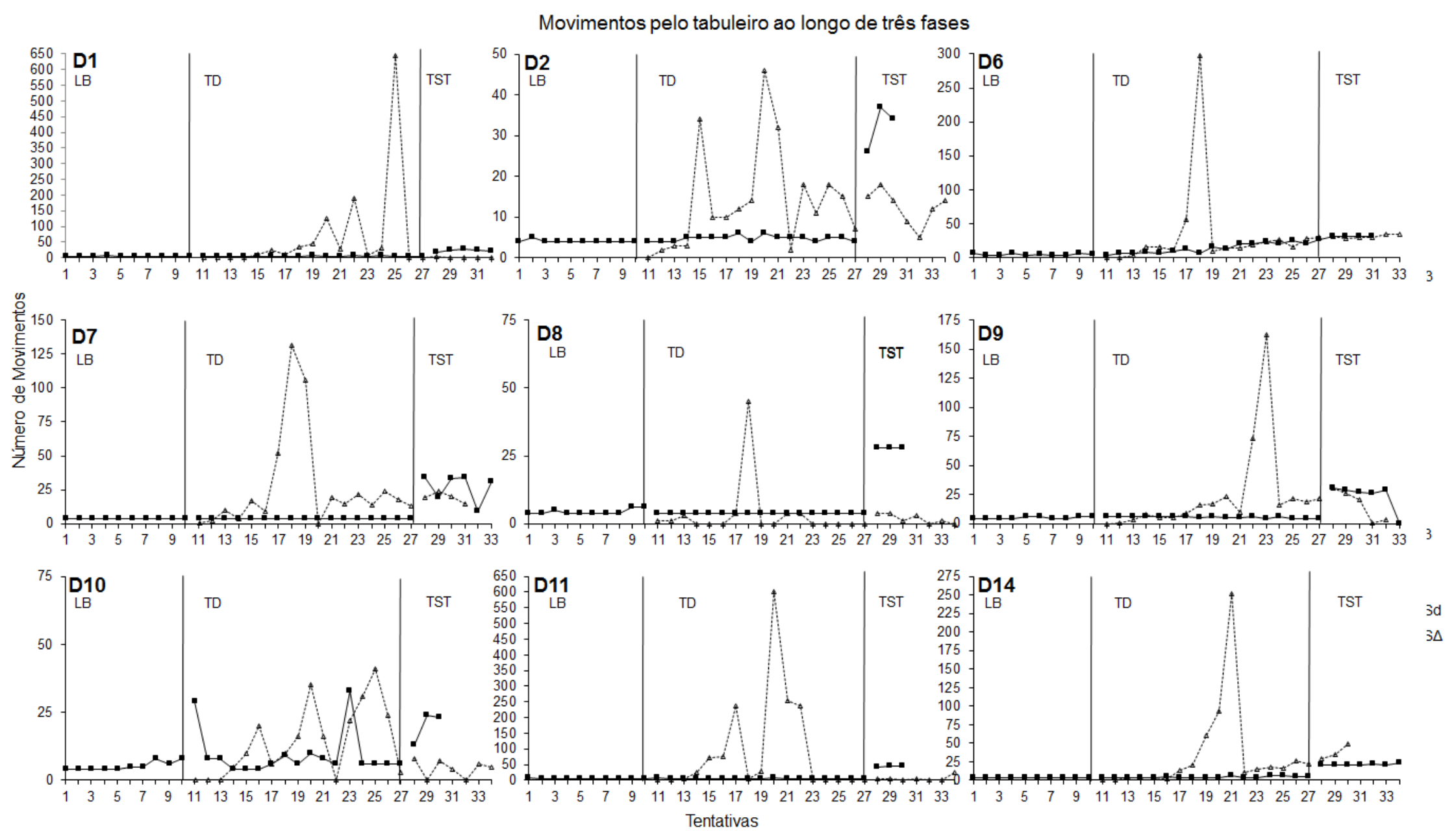

Figura 10: Número de movimentos para a produção de PA realizados por tentativa em cada condição ao longo das fases de linha de base, treino discriminativo e teste discriminativo no Experimento 2. Atentar para escalas diferentes no eixo $\mathrm{Y}$ 


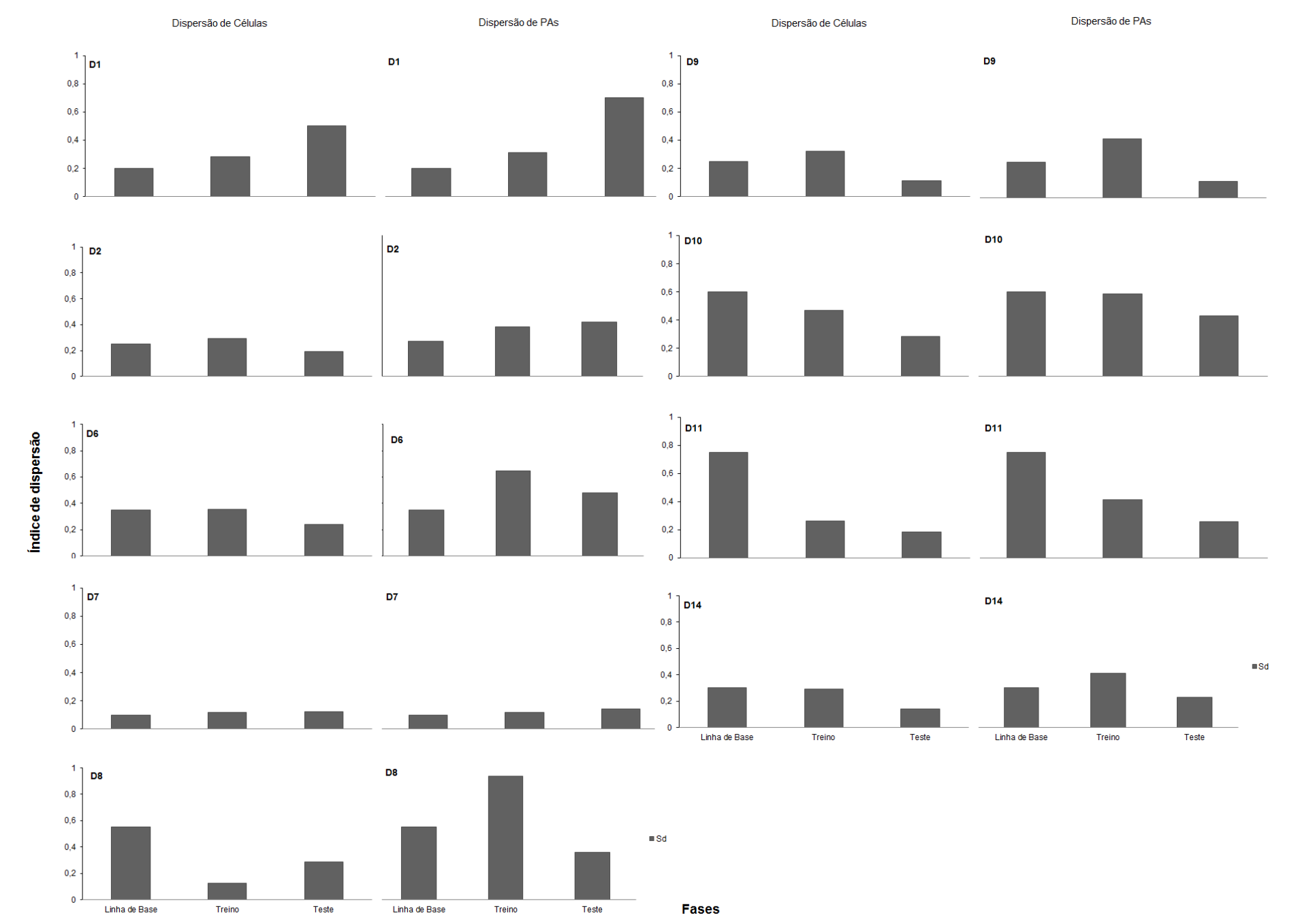

Figura 11: Índices de dispersão de células e de PAs por duplas no Experimento 2 durante a linha de base, teste discriminativo e teste discriminativo. 

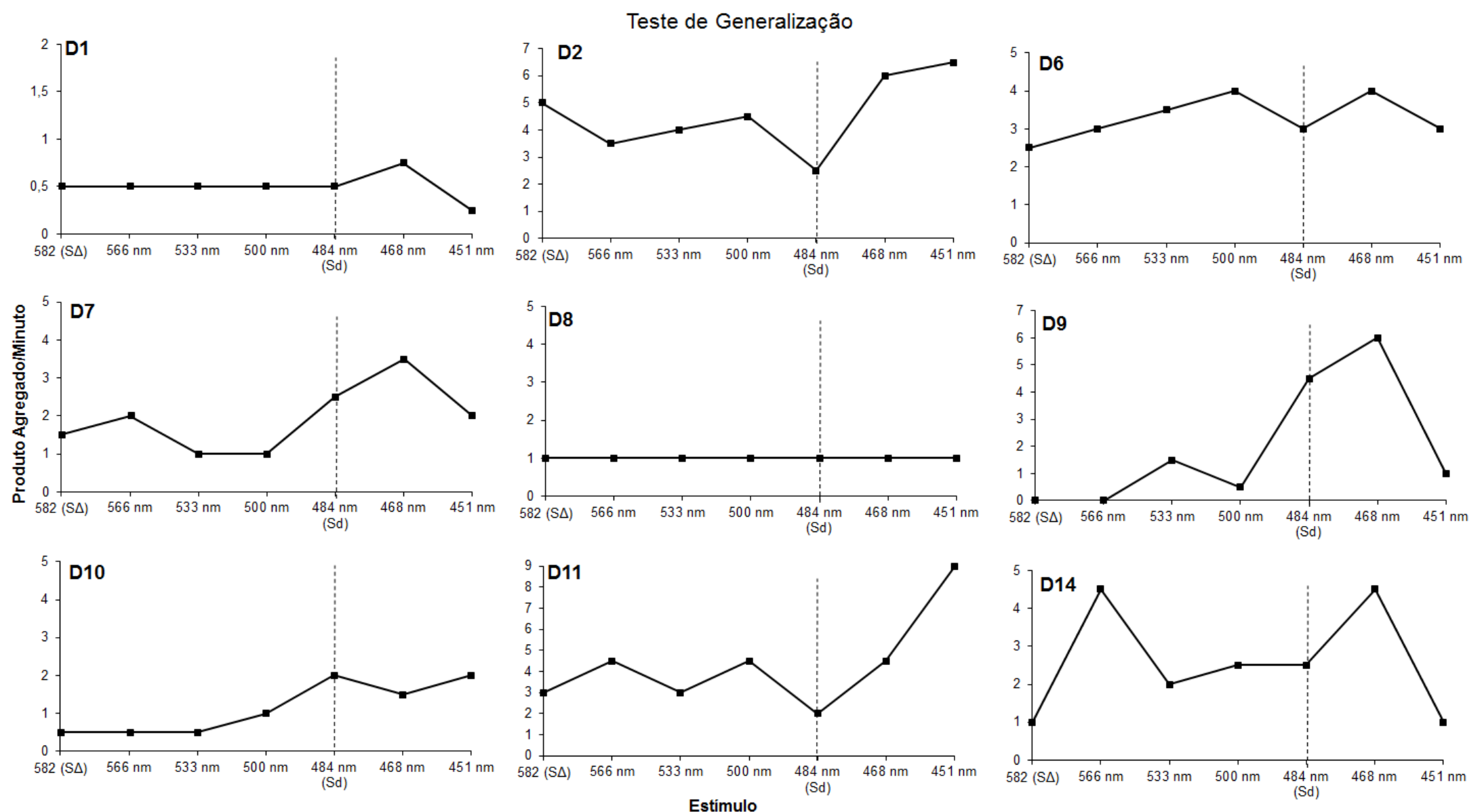

Figura 12: Taxas de produto agregado por minuto ao longo da apresentação de cada estímulo na fase de Teste de Generalização do Experimento 2. A linha vertical tracejada sinaliza a posição do $S^{\mathrm{D}}$ no gráfico. Atentar para escalas diferentes no eixo $\mathrm{Y}$ 


\section{Discussão}

Algumas alterações metodológicas foram realizadas em relação ao procedimento utilizado por Azevedo (2015) a fim de verificar se haveria aumento na discriminação em seu procedimento simplificado em metacontingência. As medidas principais foram: (1) introduzir lentamente o $S^{\Delta}$ - diminuindo o tempo de progressão do $S^{\Delta}$ e, por sua vez, aumentando o tempo da fase de treino discriminativo; (2) alterar o critério de estabilidade do teste discriminativo em relação ao treino discriminativo, diferenciando-o (de $45^{\prime}$ de inatividade em $\mathrm{S}^{\Delta}$ durante o treino passou para $60^{\prime}$ de exposição durante o teste discriminativo para ambos os estímulos); (3) verificar a possibilidade de apresentação aleatória dos estímulos durante o teste discriminativo (mudança realizada no Experimento 2); e (4) teste de generalização (mudança realizada em ambos os experimentos, diminuindo o tempo de exposição dos estímulos para 60' por vez e apresentando-os de maneira aleatória).

Quando o programa utilizado ainda estava em fase de testes, observou-se que a introdução de blackout (100 milissegundos) entre as tentativas poderia auxiliar na discriminação, especialmente quando os estímulos foram dispostos de maneira aleatória no teste discriminativo do Experimento 2 e um estímulo calhava de ser apresentado consecutivamente. Outra ferramenta que foi utilizada a fim de auxiliar a discriminação foi a introdução de um contador acumulado de acertos.

Ao comparar o tempo médio de duração das linhas de base dos experimentos, observa-se que o tempo médio dos dois experimentos foi inferior (4'32' para os dois experimentos) quando comparado ao de Azevedo (7’38'). A diminuição do tempo para a produção do PA na linha de base pode ser um indicativo que o contador de acertos tenha atuado como feedback para as duplas e também como parte das consequências 
selecionadoras do PA, embora não seja necessário para a ocorrência do PA nem da discriminação nas fases seguintes, conforme demonstrou Azevedo (2015).

A mensagem de parabéns foi apresentada concomitantemente à adição de pontos no placar. Esses dois eventos (mensagem e pontuação) atuaram como as consequências selecionadoras na metacontingência. A Figura 4 esquematiza a metacontingência dos experimentos: as consequências culturais selecionaram o culturante (CCEs + PAs), observado na linha de base. Diante da presença do estímulo $S^{\mathrm{D}}$, as consequências culturais são apresentadas e diante da presença do estímulo $S^{\Delta}$ as consequências culturais não são apresentadas. Ao final do treino discriminativo, pode-se observar que há um responder diferencial, análogo ao processo discriminativo operante, em que as taxas de PA diante do $S^{\mathrm{D}}$ são maiores que as taxas de $\mathrm{PA}$ em $\mathrm{S}^{\Delta}$.

Em função da alteração no tempo inicial de apresentação de $S^{\Delta}$ e do tempo de progressão do critério de inatividade em $\mathrm{S}^{\Delta}$ (o tempo inicial passou de 10 s para 3s; e a progressão de $5 \mathrm{~s}$ para $3 \mathrm{~s}$ ), o treino discriminativo nesta pesquisa foi mais extenso que o de Azevedo (aumento em 5 tentativas ao longo do treino), mesmo o critério de estabilidade sendo menor (neste experimento foi de 45s, enquanto em Azevedo foi de $60 \mathrm{~s})$.

Observa-se que durante o treino discriminativo, logo nas primeiras tentativas em que o $\mathrm{S}^{\Delta}$ foi introduzido, que a taxa de PA foi igual a zero e só depois ela aumentou. Isso provavelmente se deve ao fato de que os participantes não tiveram tempo suficiente para a produção do PA (como se observa também pouca ou nenhuma movimentação das peças neste início das tentativas em $\mathrm{S}^{\Delta}$ ). Depois que a discriminação foi estabelecida, algumas duplas reduziram a movimentação pelo tabuleiro diante de $\mathrm{S}^{\Delta}$, enquanto outras apresentaram padrões de movimentar-se pelo tabuleiro (embora sem emitir o PA), o que corrobora com a análise feita por Azevedo (2015) de que "para umas duplas o $\mathrm{S}^{\Delta}$ 
funcionou como uma contingência de extinção, enquanto para outras duplas funcionou como um DRO (tendo como reforço o retorno de $S^{\mathrm{D}}$ )" (p. 34). Os resultados durante o teste de discriminação do Experimento 2, no entanto, apontam que para essas duplas não houve DRO e sim uma contingência de extinção, uma vez que o estímulo $S^{\Delta}$ não era necessariamente seguido pelo $\mathrm{S}^{\mathrm{D}}$.

A introdução do segundo componente $\left(\mathrm{S}^{\Delta}\right)$ apresenta efeito de interação na taxa de produção agregada do componente fixo $\left(\mathrm{S}^{\mathrm{D}}\right)$ durante o treino discriminativo. A interação caracterizada como contraste comportamental ocorreu para 4 de 5 duplas ( D3, D5, D12, D13) no Experimento 1 e para 5 de 8 duplas (D2, D6, D7, D9 e D11) do Experimento 2.

O efeito de contraste comportamental pôde ser observado nos dois experimentos desta pesquisa e no realizado por Azevedo (2015). Embora ambas as pesquisas tenham apresentado o efeito de contraste comportamental durante o treino discriminativo, é interessante perceber que no experimento de Azevedo, o tipo de contraste observado é mais evidente no início do treino, enquanto no Experimento 1 e 2, são mais evidentes ao final do treino. Essa mudança pode ser relacionada ao aumento da extensão do treino (Killeen, 2014) bem como a introdução mais lenta do $S^{\Delta}$. Segundo Killeen (2014), o contraste comportamental evidenciado ao final do treino pode ser um indicativo de um treino discriminativo bem-sucedido.

O teste de discriminação realizado no Experimento 2 se caracterizou por apresentações aleatórias dos dois estímulos. Como a apresentação dos estímulos é aleatória, não foi possível, neste experimento, garantir a equivalência de quantidade de apresentações dos estímulos. Mesmo não havendo equivalência na quantidade de apresentação dos dois estímulos $\left(\mathrm{S}^{\mathrm{D}}\right.$ e $\left.\mathrm{S}^{\Delta}\right)$ para a maioria das duplas do Experimento 2 
durante o teste discriminativo, pode-se observar que houve a discriminação entre os dois estímulos e que ela foi estabelecida ainda durante o treino.

Ainda, observa-se que para todas as duplas desta pesquisa que as taxas de PA diante de $S^{D}$ se mantiveram maiores que as de PA diante de $S^{\Delta}$ durante todas as tentativas do teste discriminativo. Este resultado foi obtido para seis das nove duplas do experimento de Azevedo (2015).

Assim como em Vieira (2010) e Azevedo (2015), os resultados encontrados na generalização foram assistemáticos, apesar de se observar o responder diferencial aos estímulos manipulados nas fases anteriores.

Os índices de dispersão apontam mais uma semelhança ao comportamento operante, referente à variabilidade comportamental gerada pela extinção e à estereotipia relacionada à topografia de respostas reforçadas, assim como observados em Vasconcelos e Todorov (2015) e Azevedo (2015). Observou-se que a maioria das duplas mantiveramse realizando encontros nas mesmas células e nos mesmos locais do tabuleiro, com pouca variação durante a apresentação de $S^{\mathrm{D}}$.

A ordem da apresentação dos estímulos durante o teste de discriminação não parece ter influenciado significativamente os resultados obtidos no teste de generalização a ponto de gerar dados sistemáticos, assim como a prevalência de apresentação de algum dos estímulos durante o teste discriminativo para as duplas do Experimento 2 não parece também ter tido efeito sobre a generalização. Entretanto, o Experimento 2 apresentou o efeito de deslocamento de pico para cinco das duplas (D1, D2, D7, D9 e D11), efeito que não foi observado no experimento de Azevedo.

Uma diferença em relação ao procedimento realizado por Azevedo durante o teste de generalização é que, tanto no Experimento 1, quanto no Experimento 2, observaram- 
se algumas duplas que apresentaram quedas nas taxas de PA durante a apresentação do $\mathrm{S}^{\mathrm{D}}$ em relação aos demais estímulos (D2, D3, D5, D6, D11 e D14).

Uma possibilidade é de que o tipo de treino realizado em $\mathrm{S}^{\mathrm{D}}$ (para cada encontro em $\mathrm{S}^{\mathrm{D}}$ foi apresentada a consequência cultural) possa ser responsável por não manter as altas taxas de PA em $S^{\mathrm{D}}$ durante o teste de generalização e também responsável por parte falta de sistematicidade dos dados no teste de generalização: é comum, no comportamento operante, que respostas sejam mais fáceis de se extinguir quando o reforçamento é continuo. Sendo assim, durante a fase de generalização, em que há a suspensão do reforço, os participantes voltaram às taxas semelhantes à linha de base e começaram a variar os PAs durante a apresentação dos outros estímulos ( $\mathrm{S}^{\Delta}$ incluso) ou deixarem de responder.

A área de investigação de práticas culturais ainda é uma área relativamente nova, dentro da Análise do Comportamento. Ainda há que se desenvolver muitos estudos para investigar possíveis processos básicos e variáveis correlacionadas.

O objetivo desta pesquisa foi de realizar uma replicação sistemática de um experimento e observar o processo de discriminação de estímulos em situação de interação social.

Apesar da multideterminação do comportamento e do alto nível de complexidade associados aos comportamentos selecionados ontogeneticamente e culturalmente, mais uma vez demonstrou-se que é possível realizar um experimento simplificado em metacontingência, com manipulações apenas de consequências culturais. Também foi possível observar que estímulos antecedentes exercem controle na emissão de produção agregada.

Outra contribuição deste trabalho é que os dados indicam mais uma vez que processos semelhantes à seleção e à manutenção de comportamentos no nível ontogenético também ocorrem no âmbito das práticas culturais. 
Diante dos resultados obtidos neste estudo e de Azevedo (2015), algumas sugestões em relação ao procedimento utilizado podem ajudar aprimorar os resultados e a atenuar os dados assistemáticos obtidos durante o teste de generalização.

Uma sugestão para experimentos futuros seria planejar um procedimento em que, a partir de um novo treino, as funções dos estímulos $\mathrm{S}^{\mathrm{D}}$ e $\mathrm{S}^{\Delta}$ seriam revertidas e observar se o treino para respostas na cor amarela e a extinção de respostas na cor azul apresentaria taxas e resultados parecidos ao final do experimento. Contudo, o experimento deve ser cautelosamente planejado e levar em conta o custo de se realizar mais um treino, considerar um possível aumento no tempo das sessões experimentais que é uma variável importante já que elevaria o custo da participação para os voluntários.

Outra sugestão é utilizar um esquema de reforçamento intermitente nas apresentações de $S^{D}$ durante o treino e obter informações sobre este tipo de treino em metacontingência. A mudança no esquema de reforçamento poderia fortalecer padrões durante o teste de generalização (Catania, 1999) e ver se as taxas produzidas persistem por mais tempo durante a apresentação do $S^{\mathrm{D}}$ (Catania, 1999; Dinsmoor, 1995) e apresentam gradiente de generalização, como o apresentado em um experimento clássico (e.g., Guttman \& Kalish, 1956).

Uma maneira para se aprimorar os resultados obtidos durante o teste de discriminação seria garantir a apresentação em equidade de vezes de cada estímulo - o que não foi possível nesta pesquisa durante o Experimento 2.

Segundo Sidman (2008), foi a inclusão dos estímulos antecedentes na definição de comportamento que levou os analistas do comportamento a investigar o controle de estímulos (p. 128) e, ainda segundo o autor, esta área tem se mostrado capaz de aproximar a Análise do Comportamento de outras ciências, integrando e enriquecendo os campos de conhecimento sobre o comportamento (e, em especial, o comportamento humano). É 
possível que uma alteração no conceito de metacontingência que inclua o papel do ambiente na unidade de análise do terceiro nível de seleção, analogamente ao operante, também leve a novas investigações e pesquisas na área, e promovendo diálogos com as ciências humanas e naturais.

Por meio da pesquisa básica e aplicada de práticas culturais a Análise do Comportamento tem muito a oferecer para a compreensão da seleção e manutenção de práticas culturais. A compreensão dos eventos em nível cultural permite que sejam planejadas intervenções eficazes e duradouras. 


\section{Referências}

Andrade, F. A. (2015). Efeitos de mudanças sucessivas na definição de produto agregado em metacontingência. Dissertação de Mestrado. Universidade de Brasília, Brasília.

Azevedo, R. M. (2015). Controle discriminativo em metacontingência. Dissertação de Mestrado. Universidade de Brasília.

Cabral, M. D. (2014). Contingências e metacontingências envolvidas no processo legislativo da lei 12,433 de 29 de junho de 2011. Dissertação de Mestrado. Universidade de Brasília.

Carvalho, I. C. (2013). Contingências e metacontingências na Lei de Diretrizes e Bases da Educação - LDB. Dissertação de Mestrado. Universidade de Brasília.

Catania, A. C. (1999). Aprendizagem e Comportamento. Em A. C. Catania, Aprendizagem: Comportamento, Linguagem e Cognição (4ª ed., pp. 21-31). Porto Alegre: Artmed.

Costa, D. C. (2009). Dilema do Prisioneiro: O efeito das consequências individuais e culturais sobre as ecolhas de cooperação e competição. Dissertação de Mestrado. Universidade de Brasília.

Costa, D., Nogueira, C., \& Vasconcelos, L. (2012). Effects of communication and cultural consequences on choices combinations in INPDG with four participants. Revista Latinoamericana de Psicología, 44(1), 121-131.

Dinsmoor, J. A. (1995). Stimulus control: Part I. The Behavior Analyst, 18(1), 51-68.

Forero, D. D., Garcia, D. A., \& López-López, W. (2012). Análisis metacontingencial de la "Ley de Justiça y Paz" (975 de 2005) en Colombia. Revista Latinoamericana de Psicología, 44, 149-157. 
Franceschini, A. C., Samelo, M. J., Xavier, R. N., \& Huzinker, M. H. (2012). Effects on consequences on Patterns of interlocked Contingencies: A replication of a matacontingency experiment. Revista Latinoamericana de Psicología, 44, 87-95.

Glenn, S. (1986). Metacontingencies in Walden Two. Behavior Analysis and Social Action, 5(1), 2-8.

Glenn, S. S., Malott, M. E., Andery, M. A., Benvenuti, M., Houmanfar, R. A., Sandaker, I., Todorov, J. C., Tourinho, E. Z., \& Vasconcelos, L. A. (2016). Toward consistent terminology in a behaviorist approach to cultural analysis. Behavior and Social Issues, 25, 11-27.

Guttman, N., \& Kalish, H. J. (1956). Discriminability and stimulus generalization. Journal of Experimental Psychology, 51(1), 79-88.

Herrnstein, R. J. (1961). Relative and absolute strength of response as a function of frequency of reinforcement. Journal of the Experimental Analysis of Behavior, $4(3), 267-272$.

Keller, F., \& Schoenfeld, W. (1950). Principles of Psychology : a systematic text in the science of behavior. New York: Appleton-Century Crofts.

Killeen, P. R. (2014). A theory of behavioral contrast. Journal of the Experimental Analysis Behavior, 102(3), 363-390.

Leite, F. L. (2014). Efeitos de antecedentes sociais sobre a seleção de práticas culturais de complexidade progressiva. Tese de Doutorado. Universidade Federal do Pará, Belém, PA, Brazil.

Martins, A. L. (2009). O Sistema Único de Saúde: contingências e metacontingências nas leis orgânicas da saúde. Dissertação de Mestrado. Universidade de Brasília. 
Martone, R. C., \& Todorov, J. C. (2007). O desenvolvimento do conceito de metacontingência. Revista Brasileira de Análise do Comportamento, 3(2), 181190.

Moreira, M. B., Todorov, J. C., \& Nalini, L. E. (2006). Algumas considerações sobre o responder relacional. Revista Brasileira de Terapia Comportamental e Cognitiva, 8(2), 192-211.

Moreira, M., \& Medeiros, C. (2007). Princípios Básicos de Análise do Comportamento. Artmed.

Nogueira, C. P. (2009). Seleção de diferentes culturantes no dilema do prisioneiro: efeito da interação entre a consequência cultural, escolhas simultâneas ou sequenciais e a comunicação. Dissertação de Mestrado. Universidade de Brasília.

Oliveira, R. M. (2015). Metacontingência: um experimento com variabilidade operante do produto agregado. Dissertação de Mestrado. Universidade de Brasília.

Ortu, D., Becker, A., Woelz, \& Glenn, S. (2012). An iterated foir player prisioner's dilemma game with an exeternal selecting agent: a metacontingency experiment. Revista Latinoamericana de Psicología, 44(1), 111-120.

Pavanelli, S., Leite, F., \& Tourinho, E. (2014). A "modelagem" de contingências comportamentais complexas. Acta Comportamentalia, 22, 425-440.

Reynolds, G. S. (1961). Behavioral contrast. Journal of thr Experimental Analysis of Behavior, 4(1), 57-71.

Sampaio, A. (2016). Metacontingência, dilema do prisioneiro e cooperação: Efeitos da interação verbal e da forma de apresentação da consequencia cultural. Tese de Doutorado. Universidade de São Paulo. 
Sampaio, A., \& Andery, M. (2010). Comportamento social, produção agregada e prática cultural: uma análise comportamental de fenômenos sociais. Psicologia: Teoria e Pesquisa, 26(1), 183-192.

Sério, T. M. A. P, Andery, M. A., Gioia, P. S., \& Micheletto, N. (2010). Os conceitos de discriminação e generalização. Em T. Sério, M. Andery, P. Gioia, \& N. Micheletto, Controle de estímulos e comportamento operante: Uma (nova) introdução (pp. 7-26). São Paulo: EDUC.

Sidman, M. (2008). Reflections on stimulus control. The Behavior Analyst, 32(2), 127135.

Skinner, B. F. (1938). Behavior of organisms: An experimental analysis. New York: Appeton-Century-Crofts.

Skinner, B. F. (1953/2000). Ciência e comportamento humano. (J. C. Todorov, \& R. Azzi, Eds.) São Paulo: Martins Fontes.

Skinner, B. F. (1974/1995). Sobre o Behaviorismo. São Paulo: Cultrix.

Skinner, B. F. (1981). Selection by consequences. Science (213), 501-504.

Terrace, H. S. (1963). Discrimination lerning with and without "errors". Journal of the experimental analysis of behavior, 6(1), 1-27.

Todorov, J. C. (1991). O conceito de contingência na psicologia experimental. Psicologia: Teoria e Pesquisa, 7, 59-70.

Todorov, J. C. (2008). Uma revisão de revisões por ocasião dos 70 anos de O comportamento dos organismos de B. F. Skinner. Revista Brasileira de Análise do Comportamento, 4(1), 1-7.

Todorov, J. C. (2012a). Contingências de seleção cultural. Revista Brasileira de Análise do Comportamento, 8(2), 49-59. 
Todorov, J.. C. (2012b). Metacontingências e a análise comportamental de práticas culturais. Clínica e cultura, 1(1), 36-45.

Todorov, J. C. (2012c). Sobre uma definição de comportamento. Perspectivas em Análise do Comportamento, 3(1), 32-37.

Todorov, J. (2013). Conservation and transformation of cultural practices through contingencies and metacontingencies. Behavior and Social Issues, 22, 64-73.

Todorov, J. (2016). No princípio era o isolamento voluntário, agora temos que correr para recuperar o tempo perdido. Acta Comportamentalia, 24(2), 195-199.

Todorov, J. C., \& Vianney, J. (2013). Xadrez. Versão 3.7.10. Brasília, Brasil.

Todorov, J. C., Moreira, M., Prudêncio, M. R., \& Pereira, G. C. (2004). O Estatuto da Criança e do Adolescente como metacontingência. Em F. C. M. Z. S. Brandão, Sobre Comportamento E Cognição: contingências e metacontingências, contextos sócio-verbais e o comportamento do terapeuta. Santo André: ESETec.

Toledo, T., Benvenuti, M., Sampaio, A., Marques, N., Cabral, P., Araújo, L., \& Moreira, L. (2015). Free culturant: a software for the experimental study of behavioral and Cultural Selection. Psychology \& Neuroscience, 8, 366-384.

Vasconcelos, I. G., \& Todorov, J. C. (2015). Experimental analysis of the behavior of persons in groups: Selection of an aggregate product in a metacontingency. Behavior and Social Issues, 24, 111-125.

Vichi, C. (2012). Efeitos da apresentação intermitente de consequências culturais sobre contingências comportamentais entrelaçadas e seus produtos agregados. Tese de Doutorado. Universidade Federal do Pará, Belém, PA, Brasil.

Vichi, C., Andery, M. A., \& Glenn, S. S. (2009). A metacontingency experiment: The effect of contingent consequences on patterns of interlocking contingencies of reinforcement. Behavior and Social Issues, 18, 41-57. 
Vieira, A. C. (2010). Condições antecedentes participam de metacontingências? Dissertação de Mestrado. Pontificia Universidade Católica de São Paulo, São Paulo, Brasil. 


\section{Anexo - TCLE \\ Termo de Consentimento Livre e Esclarecido - TCLE}

Convidamos o (a) Senhor(a) a participar da pesquisa Controle por Antecedentes em Produção Agregada, sob a responsabilidade do pesquisador Adriana de Souza Miranda, orientado pelo Prof. Dr João Claudio Todorov. O objetivo da pesquisa é investigar comportamentos em situação de interação social, através de uma atividade colaborativa.

A sua participação se dará por meio da participação em um jogo de computador, que será jogado em dupla, em um único encontro com um tempo estimado de uma hora de duração para sua realização.

$\mathrm{O}$ (a) senhor(a) receberá todos os esclarecimentos necessários antes e no decorrer da pesquisa e lhe asseguramos que seu nome não aparecerá sendo mantido o mais rigoroso sigilo pela omissão total de quaisquer informações que permitam identificá-lo(a). Este estudo não pretende trazer riscos psicológicos, físicos ou qualquer outro risco, bem como não pretende trazer nenhuma despesa para o participante. Caso haja algum dano direto ou indireto decorrente de sua participação na pesquisa, você poderá ser indenizado, obedecendo-se as disposições legais vigentes no Brasil. Se você aceitar participar, estará contribuindo para o maior conhecimento sobre os processos básicos de práticas culturais.

$\mathrm{O}$ (a) Senhor(a) pode se recusar a responder (ou participar de qualquer procedimento) qualquer questão que lhe traga constrangimento, podendo desistir de participar da pesquisa ou retirar seu consentimento em qualquer momento sem nenhum prejuízo para o(a) senhor(a), mesmo que ela já tenha sido iniciada. Sua participação é voluntária, isto é, não há pagamento por sua colaboração bem como não haverá ônus se optar por não participar.

Os resultados da pesquisa serão analisados e publicados, mas sua identidade não será divulgada, sendo guardada em sigilo. Para qualquer outra informação o (a) Sr (a) poderá entrar em contato em qualquer momento com o pesquisador no endereço UNBICC Sul - Instituto de Psicologia - Laboratório AEC - Subsolo, pelo email: 
adrianamirandapsi@gmail.com ou ainda pelo telefone 61 98403-8430, podendo efetuar chamadas a cobrar.

Este projeto foi aprovado pelo Comitê de Ética em Pesquisa da Faculdade de Ciências da Saúde (CEP/FS) da Universidade de Brasília. As dúvidas com relação à assinatura do TCLE ou os direitos do participante da pesquisa podem ser esclarecidos pelo telefone (61) 3107-1947 ou do e-mail cepfs@unb.br ou cepfsunb@gmail.com. O CEP/FS se localiza na Faculdade de Ciências da Saúde, Campus Universitário Darcy Ribeiro, Universidade de Brasília, Asa Norte.

Caso concorde em participar, pedimos que assine este documento que foi elaborado em duas vias, uma ficará com o pesquisador responsável e a outra com o Senhor(a).

Nome / assinatura

Adriana de Souza Miranda - Pesquisadora Responsável

Nome e assinatura

Brasília, de de 2016 